\title{
A Systematic Review of Statistical and Machine Learning Methods for Electrical Power Forecasting with Reported MAPE Score
}

\author{
Eliana Vivas ${ }^{1, *(\mathbb{D}}$, Héctor Allende-Cid $^{1}\left(\mathbb{D}\right.$ and Rodrigo Salas ${ }^{2}(\mathbb{D}$ \\ 1 Escuela de Ingeniería Informática, Pontificia Universidad Católica de Valparaíso, Brasil 2950, Valparaíso, \\ Chile; hector.allende@pucv.cl \\ 2 Escuela de Ingeniería C. Biomédica, Universidad de Valparaíso, Chacabuco 2092-2220, Valparaíso, Chile; \\ rodrigo.salas@uv.cl \\ * Correspondence: eliana.vivas.r@mail.pucv.cl; Tel.: +56-9-870-25259
}

Received: 29 October 2020; Accepted: 10 December 2020; Published: 15 December 2020

\begin{abstract}
Electric power forecasting plays a substantial role in the administration and balance of current power systems. For this reason, accurate predictions of service demands are needed to develop better programming for the generation and distribution of power and to reduce the risk of vulnerabilities in the integration of an electric power system. For the purposes of the current study, a systematic literature review was applied to identify the type of model that has the highest propensity to show precision in the context of electric power forecasting. The state-of-the-art model in accurate electric power forecasting was determined from the results reported in 257 accuracy tests from five geographic regions. Two classes of forecasting models were compared: classical statistical or mathematical (MSC) and machine learning (ML) models. Furthermore, the use of hybrid models that have made significant contributions to electric power forecasting is identified, and a case of study is applied to demonstrate its good performance when compared with traditional models. Among our main findings, we conclude that forecasting errors are minimized by reducing the time horizon, that ML models that consider various sources of exogenous variability tend to have better forecast accuracy, and finally, that the accuracy of the forecasting models has significantly increased over the last five years.
\end{abstract}

Keywords: electric power; forecasting accuracy; machine learning

\section{Introduction}

Electric power forecasting plays a substantial role in the administration and balance of current power systems. The load forecasts help to identify strategies to optimize the operating mechanisms in a determined period and thus ensure the demand even in situations adverse to the system [1]. Accompanying the rapid advances in forecasting theory [2,3] and machine learning [4-6], the technology in the energy forecasting research area has also developed rapidly [7]. Additionally, the popular prediction methods for the generation and demand of energy can be divided into two categories. The first category is statistical or mathematical methods, and the second category is modern statistical-learning-based methods (also known as machine learning). In addition, hybrid methods can be found that apply not only statistical tools but also other elements, such as mathematical optimization or signal processing [8,9]. Additionally, other authors [10] consider hybrid approaches that focus on a series of individual methods, such as noise reduction, seasonal adjustment and clustering, to process the data in advance, whereas combined methods use weight coefficients. With respect to the techniques implemented to forecast energy in recent years, in the international context, we can 
find a wide diversity; e.g., the application of kernel-based multitask learning methodologies [11], energy load forecasting methodologies based on deep neural networks as in [12,13], methodologies based on the classic time series approach as in [14-16], and mathematical representations as in [17-19]. Developing a model that achieves the highest forecasting precision in the context of electric power has been the object of study in recent years. Additionally, the determination of the appropriate input variables in load forecasting constitutes an important part of the forecasting procedure [20]. Due to the importance of the area, several review papers have appeared that present insights into current applications and future challenges and opportunities [21,22]. However, existing review papers examine the applications of a single model, e.g., an ANN [23], or cover only one energy domain, e.g., solar radiation prediction $[24,25]$, and do not perform comparisons among specific metrics, such as MAPE, for multiple applications. Therefore, a systematic review to identify the type of model that has the highest propensity to show precision in the forecast is the main objective of this paper.

\section{Motivation and Scope of the Review}

The number of papers published on the topic of electric power forecasting has been growing at an exponential rate throughout the last decade, as Figure 1 shows. The order of magnitude of the increase in the number of scientific publications on the subject revolves around $61.59 \%$, between 2016-2020, with respect to 2011-2015. Generally, the studies are site-specific, and the results strongly depend on the nature of the model and the time horizon of the forecast, along with a large number of other characteristics pertaining to the data and models. This is a major limitation, which makes a generalization of the results difficult. A test of a given model over all different mentioned factors is needed to measure the average effect of the model [25]. Consequently, the contribution of this paper is to present the state-of-the-art of models in electric power systems and discuss their likely future trends, considering:

- (I) The models that tend to provide precision in electric power forecasts according to the literature.

- (II) Exogenous sources that tend to lead to accurate forecasting of electrical energy according to the literature.

- (III) Relationships between the times of forecasting and the accuracy of existing models.

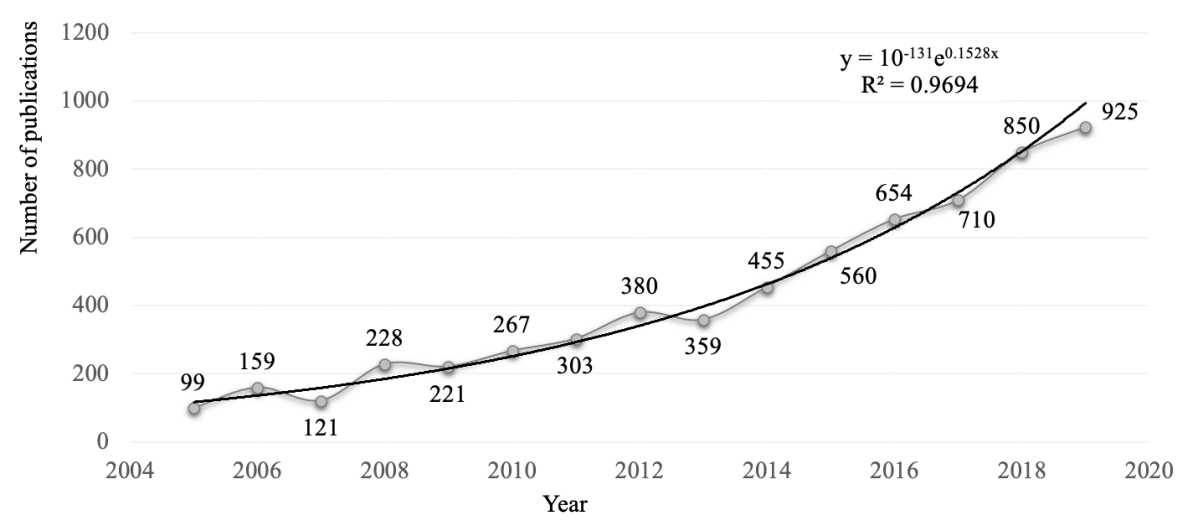

Figure 1. Number of articles published per year. The line represents an exponential fit, highlighting the yearly growth trend. The publications from 2020 are excluded since only partial data are available.

The rest of this paper is organized as follows. In Section 2, the methodology of the research is presented. In Section 3, a description of the data set is presented. In Section 4, a performance analysis of the forecasting models is presented, and finally, the overall discussion and conclusions are presented. 


\section{Theoretical and Referential Framework}

This chapter presents an analysis of the documents found in the literature during the last 15 years on the subject of electric power forecasting.

\subsection{Selection Criteria}

The number of documents published on the topic of electric power forecasting has been growing at an exponential rate throughout the last 15 years, as Figure 1 shows. We analyze in the review the documents published for electric power forecasting contained in SCOPUS, Web of Sciences, Science Direct and IEEE (Figure 2), according to the criteria shown in Figure 3 and following the steps of the PRISMA (Preferred Reporting items for Systematic Review and Meta-Analyses) methodology.

A large number of papers published between January 2005 and March 2020 were analyzed. The qualitative and quantitative synthesis of the analysis was collected from 164 documents selected based on the criteria shown in Figure 3; the documents that only forecast electric power in buildings, universities, homes, and rooms were excluded; likewise, if the time horizons are not mentioned in the Abstract, the article was also skipped in our research. Similarly, if in an article, MAPE was not used as a criterion for accuracy, it was not considered in our review. When considering the accuracy of the results reported by the selected papers in terms of the MAPE Equation (1), we can compare samples of different magnitudes, thus ensuring a common basis for intercomparison analyses.

It is important to highlight that under our filtering criteria a significant volume of valuable references may have been excluded; in this sense, our searches may not be specific. If the readers are interested exclusively in consulting documents related to forecasting under machine learning methods, then they could consult [21], or if they are interested in specific documents on solar energy, they could consult [25]; in the case of documents associated with the forecast under classical statistical techniques, there are specific documents that can be consulted, such as [26].

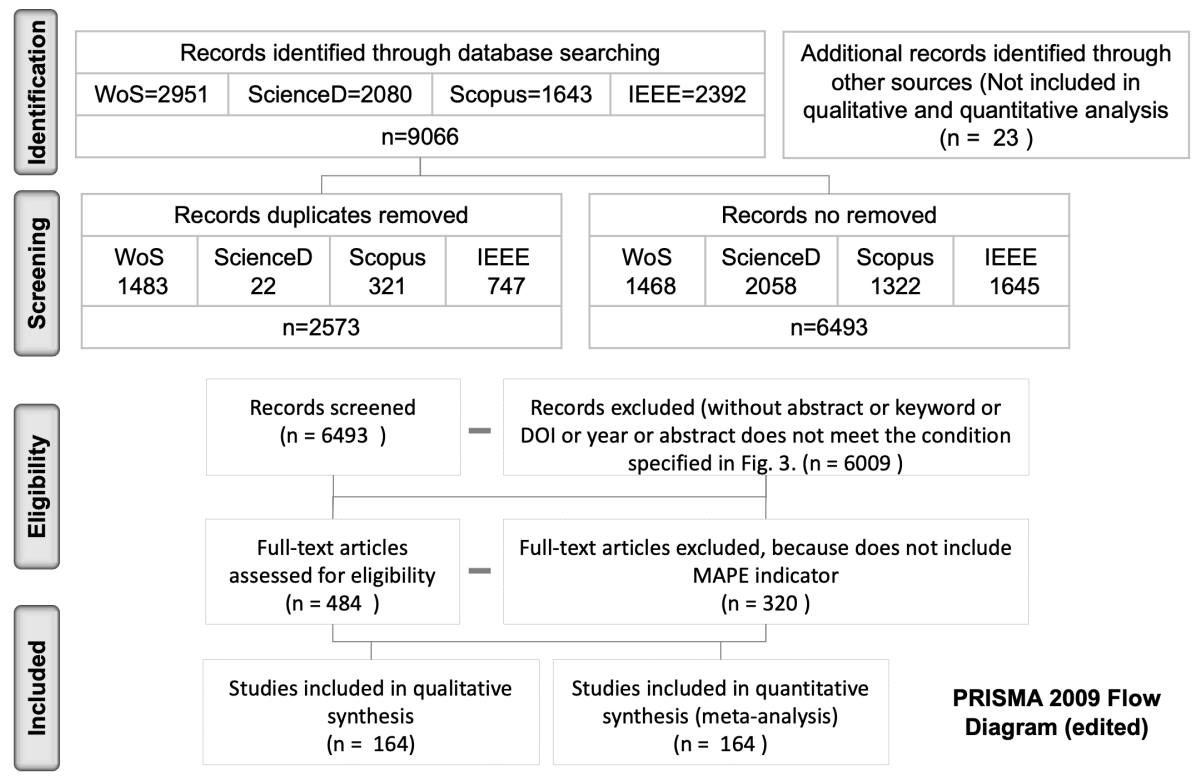

Figure 2. PRISMA Flow Diagram. 


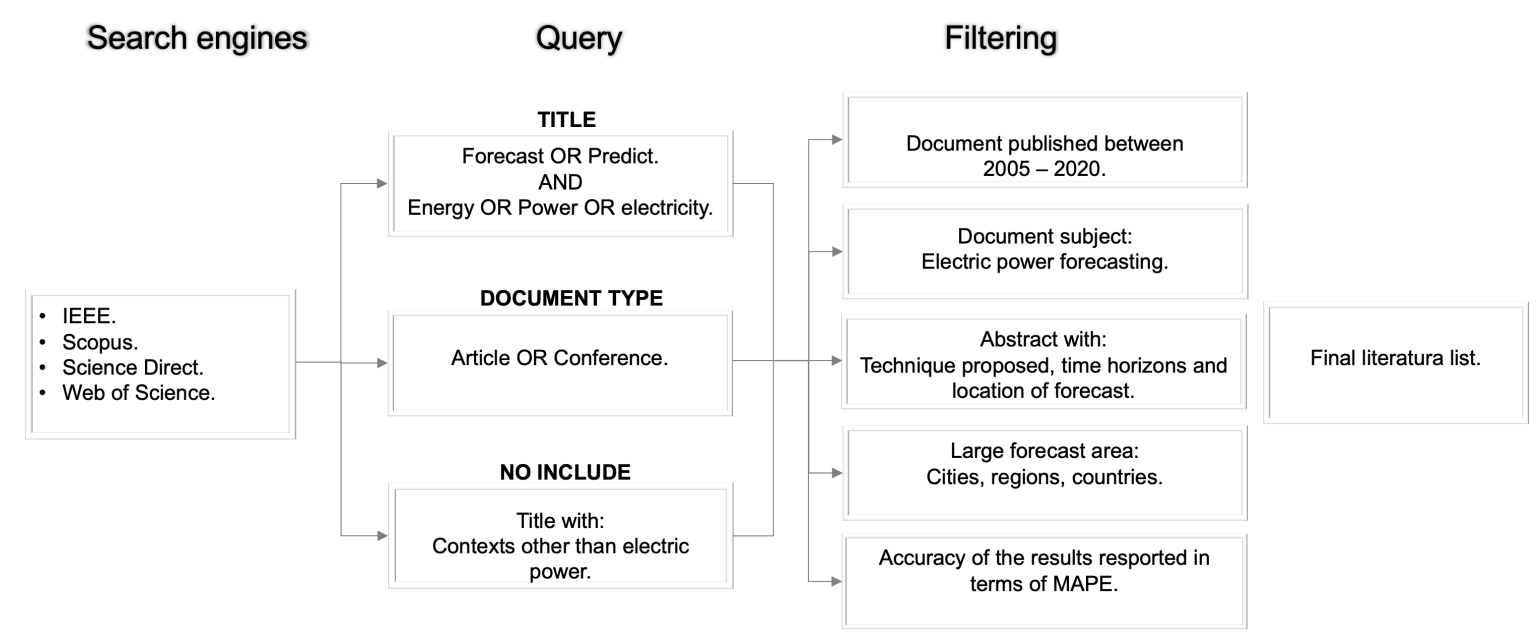

Figure 3. Search methodology for finding relevant literature.

\subsection{Statistical Indicators of Accuracy in Electric Power Forecasting}

The number of papers from the publications we studied that are eligible according to the criteria was 164. We collected the mean absolute percentage error (MAPE), a statistical indicator of accuracy. This index indicates an average of the absolute percentage errors (Equation (1)); the lower the MAPE, the higher is the accuracy [27].

$$
M A P E=\frac{1}{m_{k}} \sum_{k=1}^{m}\left|\frac{t_{k}-y_{k}}{t_{k}}\right| * 100
$$

where $t_{k}$ is the actual value of electric power, $y_{k}$ is the forecasting value produced by the model, and $m$ is the total number of observations. The final quality-controlled database from the 164 documents contained 4883 entries (MAPE, type of MAPE, country, date, input variables, model, type of model, latitude, longitude, and size of sample), and we saved 257 entries associated with a MAPE value linked to the best model proposed in the cases of study with data from 33 countries. The locations are represented on the world map in Figure 4. We can see that the studied publications cover all continents. Occupying the first positions in the list of the countries with the most electrical energy forecast documents, under the criteria used, are Australia, China, Iran, and Turkey.

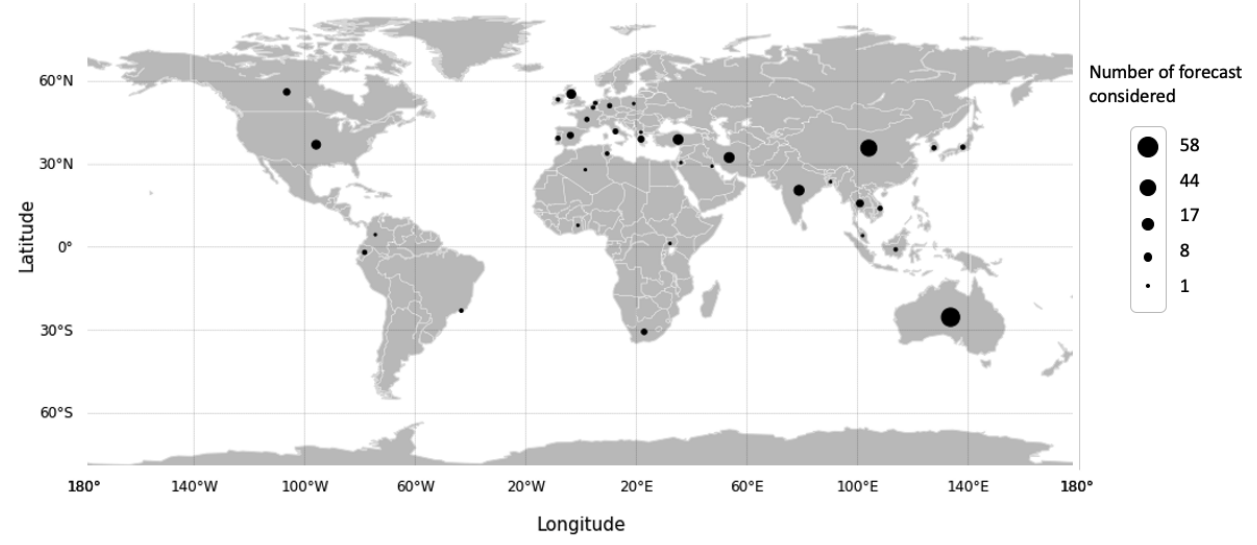

Figure 4. Number of forecasts by country considered in the review.

\section{Description of the Dataset}

The analysis was performed from five perspectives: the class of a forecasting model (MSC or ML), the type of model (hybrid or not), the time horizon, and the input variables and performance trend 
over time (MAPE). The dataset analyzed in this paper contains 257 entries associated with a MAPE value linked to the best model proposed in the document.

The MAPE value was classified according to the criteria drawn up by [28], which contain typical MAPE values for business and industrial data and their interpretation in four evaluation criteria (in our case, four prediction capabilities); this table was used in [29-32], and can be seen in Table 1.

Table 1. MAPE qualitative criteria.

\begin{tabular}{ll}
\hline MAPE (\%) & Prediction Capability \\
\hline$<10$ & Highly accurate prediction (HAP) \\
$10-20$ & Good prediction (GPR) \\
$20-50$ & Reasonable prediction (RP) \\
$>50$ & Inaccurate prediction (IPR) \\
\hline
\end{tabular}

Table 2 shows that of the 164 documents processed in the systematic review, 99 contain a highly accurate prediction (HAP). Additionally, more ML documents with an HAP were found than MSC documents. Regarding the sources of variability considered by the documents that contained HAPs, it can be seen that multivariate models have a higher recurrence than univariate models. As explained in [10], despite the introduction of artificial intelligence, each of the individual methods are still not able to produce the desired outcomes because of their disadvantages. For instance, neural networks attain local optimal results instead of global optimal results. Expert systems excessively rely on knowledge and cannot always obtain optimal results, whereas grey prediction systems are suitable for exponential growth models. Thus, by considering every method's merits and taking full advantage of them, the concept of hybrid and combination methods developed rapidly.

Table 2. Systematic review documents. Techniques type used in electric power forecast and qualitative values of the average MAPE.

\begin{tabular}{llllcll}
\hline \multirow{2}{*}{ MAPE } & \multirow{2}{*}{ Type } & \multicolumn{2}{c}{ Multivariate Model } & \multicolumn{2}{c}{ Univariate Model } & Total \\
\cline { 3 - 7 } & & Not Hybrid & Hybrid & Not Hybrid & Hybrid & \\
\hline HAP & ML & {$[33-72]$} & {$[6,27,73-91]$} & {$[1,14,17,18,92-107]$} & {$[29,32,85,108-122]$} & 99 \\
\hline HAP & MSC & {$[15,123-147]$} & {$[148,149]$} & {$[1,14,17,18,92-107]$} & {$[19,150-152]$} & 52 \\
\hline GPR & ML & {$[153-157]$} & {$[158]$} & {$[159-162]$} & - & 10 \\
\hline GPR & MSC & {$[16,163]$} & - & - & - & 2 \\
\hline RP & ML & {$[164]$} & - & - & - & 1 \\
\hline Total & & $\mathbf{7 4}$ & $\mathbf{2 4}$ & $\mathbf{4 4}$ & $\mathbf{2 2}$ & $\mathbf{1 6 4}$ \\
\hline
\end{tabular}

\subsection{Forecasting Horizon}

Figure 5 shows that the minimum MAPE values $(<2)$ were reached more frequently when the forecast time horizon is $5 \mathrm{~min}$. 


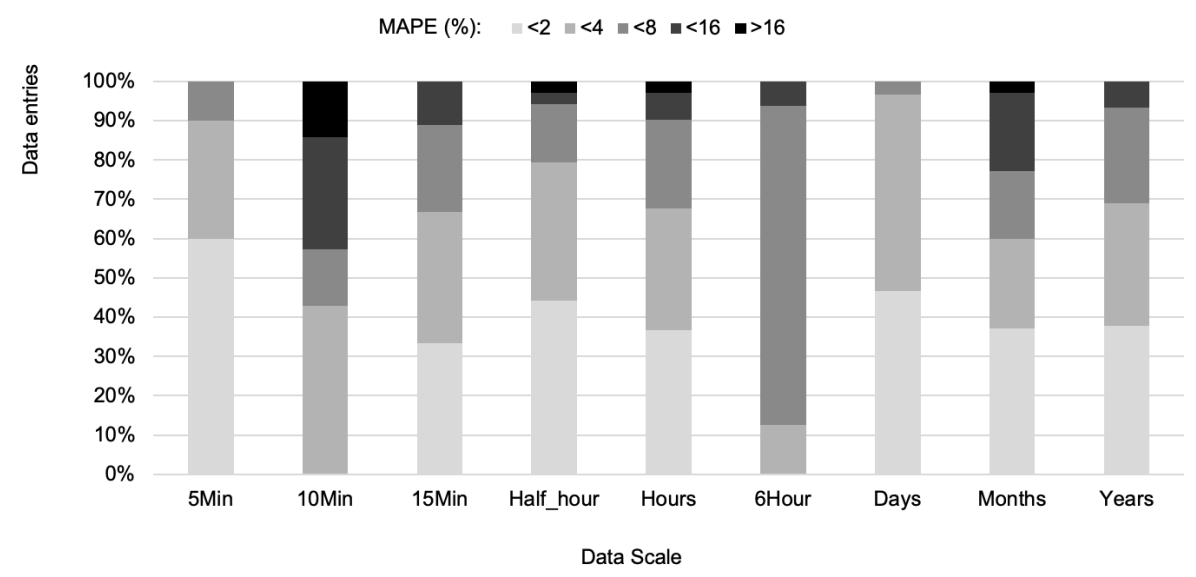

Figure 5. MAPE value interval and the percent of forecasts extracted from the 164 documents considered by time horizon.

\subsection{Exogenous Influence}

Because forecasting electric power demand is typically based on historical electricity consumption and its relationship with exogenous influences, such as gross domestic product (GDP), population, urbanization, income and exports, research on forecasting electric power demand has evolved using both univariate and multivariate time-series models [15].

Similarly, weather associated variables such as humidity, temperature, and dew point are pertinent for electric power forecasting for extensive time scales. For short-term forecasting such as minutes ahead, the climate changes are already captured in the electric power series [165]. Forecasting models using only previous electricity data (univariate) have been shown to provide HAP and to perform better than models that also use weather variables as exogenous influences (multivariate) [166]. Nevertheless, the use of weather influences was found to be beneficial for electric power forecasting horizons beyond several hours $[166,167]$. In Figure 6, it can be seen that the precision of the electric energy forecast on average tends to improve when various sources of variability are considered. In our sample of filtered documents, the average MAPE is lower for the forecasts whose models consider sources of variability from the calendar information, weather information, and economic or sociodemographic information, as in $[60,125,130,146]$.

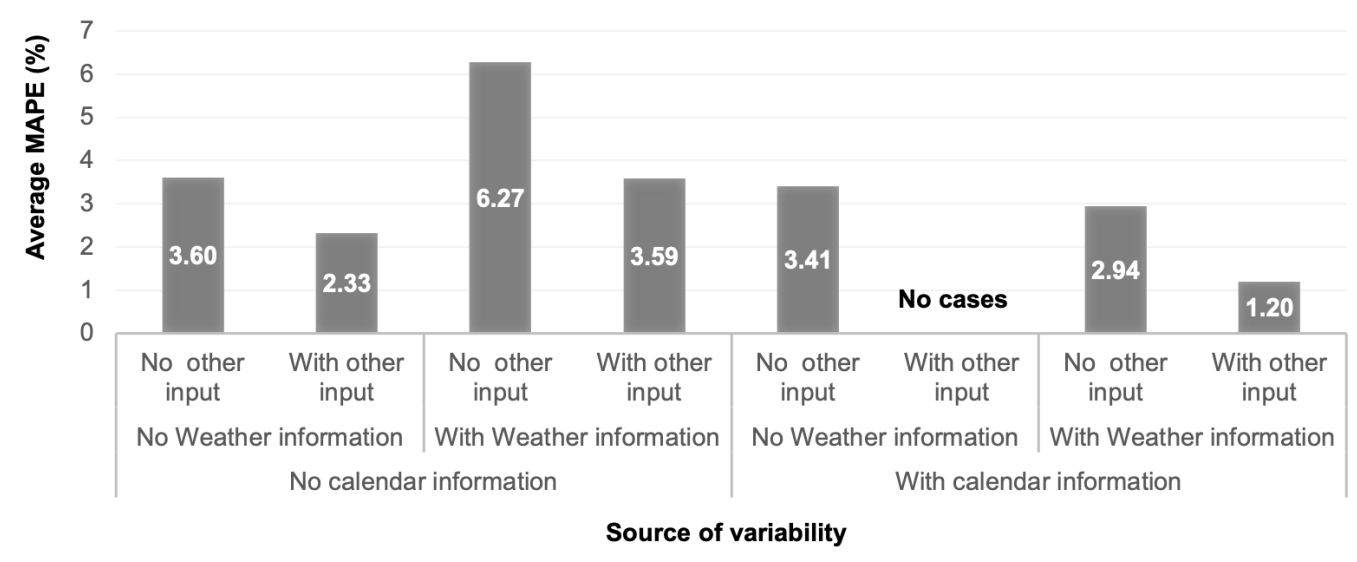

Figure 6. Average MAPE according to the considered source of variability.

\section{Classes of Forecasting Models}

From the multitude of methods that have been tested and evaluated, the ML and MSC classes seem to be the main competitors. 


\subsection{Classical Statistical Models}

A popular technique such as time series forecasting is applied in several areas [25]. The most widely used statistical method is the ARIMA of Box and Jenkins, which was applied with more force during the eighties, when intelligent systems began to appear [168]. Several time series models make use of the high autocorrelation for small lags in the time series of electric power, and supply electric power forecasts using only previously measured values of electric power as input.

From the multitude of methods that have been tested and evaluated in this review, in this class, regression analysis and ARIMA modeling seem to be the main competitors (Figure 7).

\subsection{Classical Regression in the Time Series Context}

To explain linear regression in the the context of time series, we assume some output or dependent time series. Assume $x_{t}$ for $t=1, \cdots, n$, is being influenced by a collection of possible inputs or independent series, such as $z_{t_{1}}, z_{t_{2}}, \cdots, z_{t_{q}}$, where we first regard the inputs as fixed and known [169]. We express this relation through the linear regression model:

$$
x_{t}=\beta_{0}+\beta_{1} z_{t 1}+\beta_{2} z_{t 2}+\cdots+\beta_{q} z_{t q}+w_{t}
$$

where $\beta_{0}, \beta_{1}, \cdots, \beta_{q}$ are unknown fixed regression coefficients, and $w_{t}$ is a random error or noise process consisting of independent and identically distributed (iid) normal variables with a zero mean and variance $\sigma_{w}^{2}$. For time series regression, it is rarely the case that the noise is white, and we will need to eventually relax that assumption.

Classical regression models have been used in several academic papers for electric power forecasting $[97,98,102,124,130,134,138,140]$, reaching an accuracy in the forecast with an average MAPE value of $1.569 \%$. Classical regression is often insufficient for explaining all of the interesting dynamics of a time series; instead, the introduction of correlations that may be generated through lagged linear relations led to the autoregressive (AR) and autoregressive moving average (ARMA) models that were presented in $[169,170]$. Adding nonstationary models to the mix led to the autoregressive integrated moving average (ARIMA) model popularized in the landmark work by Box and Jenkins $[169,171]$.

\subsection{Autoregressive Integrated Moving Average}

Autoregressive models are based on the idea that the current value of the series, $x_{t}$, can be explained as a function of $p$ past values, $x_{t-1}, x_{t-2}, \cdots, x_{t-p}$, where $p$ determines the number of previous steps required to forecast the current value [169].

The acronym ARIMA refers to an autoregressive integrated moving average model. ARIMA models can be applied to non-stationary data, and when the data are seasonal, the SARIMA model can be implemented. The ARIMA and SARIMA models have been used in many studies for forecasting [14-16,99,100,103,127,136], reaching forecast accuracies with an average MAPE value of $3.214 \%$. A typical ARIMA $(p, d, q)$ model can be expressed by Equation (3), where the variable $u_{t}$ is replaced by a new variable $w_{t}$ obtained by differencing $u_{t} d$ times [25]:

$$
w_{t}=(1-B)^{d} u_{t}
$$

\subsection{Machine Learning (ML) Models}

ML methods have been suggested in the academic literature as an alternative to MSC methods for time series prediction, with the same objective. They attempt to improve the forecasting accuracy precision by minimizing some loss functions, as for example the sum of squared errors. The distinction between ML and MSC is in how the minimization is performed: the ML methods use nonlinear algorithms while the MSC method use linear processes. The ML methods require a greater dependence on computer science to be implemented and are more demanding than MSC methods, as they are positioned at the intersection of MSC and computer science [172]. There are several approaches 
developed under ML theory. In this review, artificial neural networks (ANNs), support vector machines (SVMs), decision trees (DTs), adaptive neuro fuzzy inference systems (ANFISs), and recurrent neural networks (RNNs) were found to support the bases of the models that were implemented more frequently in electric power forecasting (Figure 7).

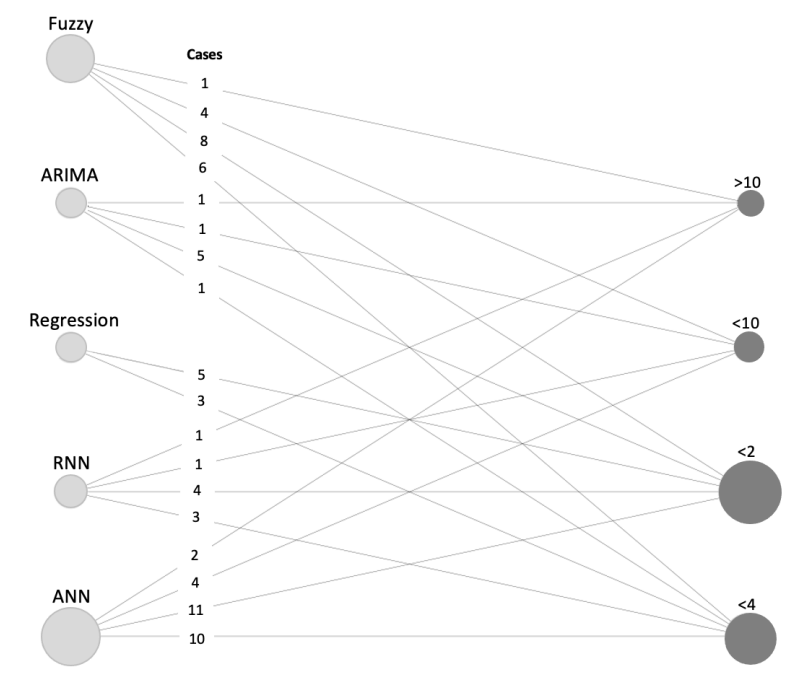

Figure 7. Graph with nodes weighted by sample size for the case of the techniques (light-gray node) and probability of occurrence for the MAPE intervals (dark-gray node).

\subsubsection{Artificial Neural Networks (ANN)}

Neural networks have been the subject of great interest for many decades due to the desire to understand the brain and to build learning machines [173]. A neural network is an interconnected assembly of simple processing elements, units or nodes whose functionalities are loosely based on animal neurons. The processing ability of a network is stored in the inter-unit connection strengths, or weights, obtained by a process of adaptation to, or learning from, a set of training patterns [174].

The ANN models have been used in many studies for electric power forecasting $[6,39,44,46,48,53-$ $55,57-62,65,70,75,77,81,82,86,108,153,155,165,175,176]$ and have reached a forcasting accuracy with an average MAPE value of $3.781 \%$.

\subsubsection{Recurrent Neural Networks (RNN)}

Models known as a recurrent neural networks allow feedback connections; these models define nonlinear dynamical systems but do not have simple probabilistic interpretations [173]. RNN models have been used in many studies for electric power forecasting $[64,69,71,73,88,90,157,177,178]$ and have reached a forecasting accuracy with an average MAPE value of $3.610 \%$.

\subsubsection{Fuzzy Neural Network-Based Forecasting Methods}

Fuzzy logic systems (or, simply, fuzzy systems (FSs)) and neural networks are universal approximators; that is, they can approximate any nonlinear function (mapping) with any desired accuracy and have found wide application in the identification, planning, and model-free control of complex nonlinear systems, such as robotic systems and industrial processes. Fuzzy logic offers a linguistic (approximate) approach to drawing conclusions from uncertain data, and neural networks offer the capability of learning and training with or without a teacher (supervisor) [179].

Fuzzy logic algorithms have been used in many studies for electric power forecasting $[10,27,33$, $45,50,52,63,79,80,83,85,91,113,118,122,154,160,180,181]$ and have reached a forecasting accuracy with an average MAPE value of $4.013 \%$. 


\subsubsection{Support Vector Machines (SVMs)}

Support vector machines are supervised learning algorithms used for solving binary classification and regression problems. The main idea of support vector machines is to construct a hyperplane such that the margin of separation between the two classes is maximized. In this algorithm, each of the data points is plotted as a data point in n-dimensional hyperspace. Then, a hyperplane that maximizes the separation between the two classes is constructed [182]. This technique was originally designed for binary classification but can be extended to regression and multiclass classification [173]. Support vector regression algorithms have been used in many studies for electric power forecasting $[41,47,49,76,109,110,112,114$, $119,164,183-185]$ and have reached a forecasting accuracy with an average MAPE value of $4.326 \%$.

\section{Evaluation of Model Accuracy}

As can be seen in Table 3, as mentioned in [77], there are many factors, such as economic development, regional industrial production, holiday periods, weather conditions, social change, electricity price, and population, that are unavoidable, affect electric power randomly, and allow the data to demonstrate different features.

Short-term load forecast models that rely on weather information require the prediction of weather parameters for the next few hours or at most the next few days [75]. Similarly, economic indicators and electrical infrastructure measures are usually useful in forecasting electric power with a long forecast horizon, e.g., a prediction of the annual peak load at least one year in advanced [39]. However, in the daily peak load forecasting for the following month, these indicators are not effective, since the forecast step and horizon are too short to observe their effect [75]; this behavior is shown in Table 3.

Similarly, from Figure 8, it can be seen that among the records of documents that reach HAP, the average MAPE value is lower in the frameworks that implement hybrid models of ML and multivariate dependency, such as those developed in [6,27,73-91]. To verify the hypotheses of the differences in the means and variances in the MAPE, three hypothesis tests are carried out. Table 4 shows that for small and medium effects, the alternative hypothesis on the minor indicates that the MAPE is accepted for the ML model, based on a hybrid method and with multivariate dependencies.
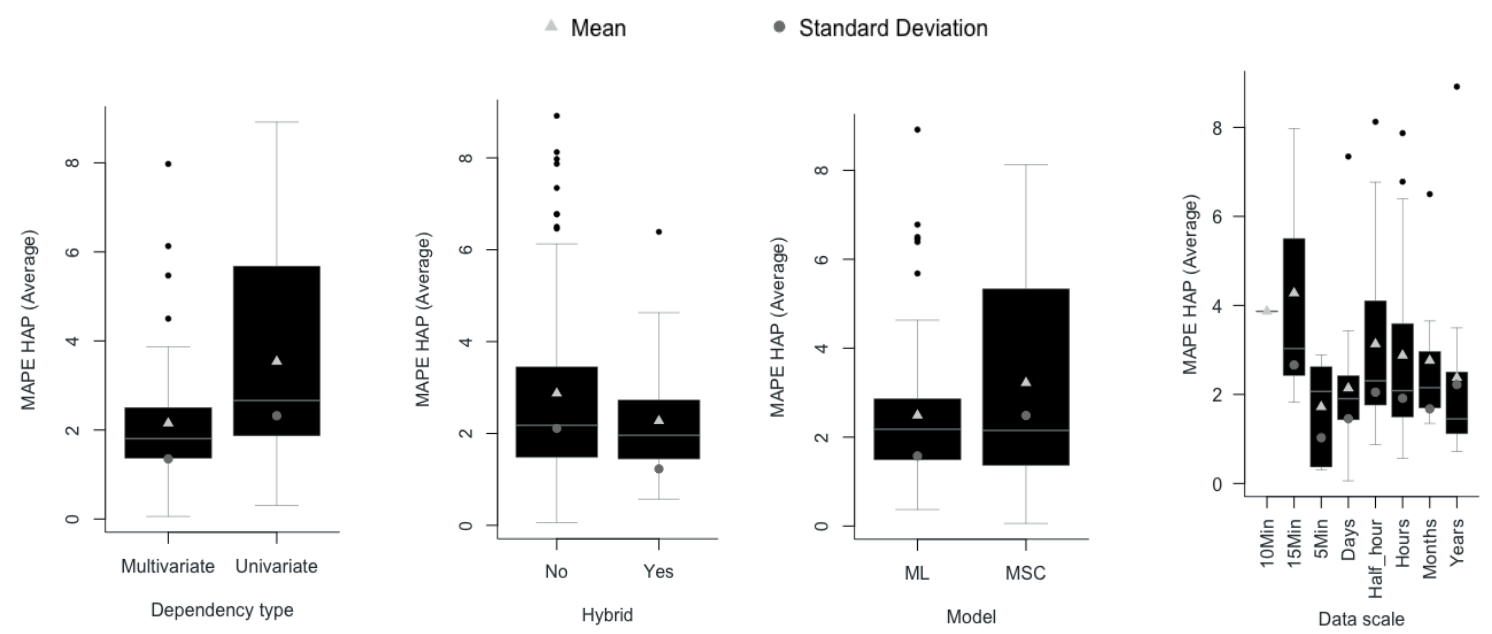

Figure 8. Boxplot of the papers included in the systematic review, with HAP-MAPE. 
Table 3. Summary of the papers included in the systematic review, with a HAP-MAPE, hybrid ML forecasting approach and multivariate model. The abbreviations are displayed in Abbreviations Section. ${ }^{1 /}$ Average MAPE; ${ }^{2 /}$ Approximate sample size. The Classification of the forecasting models can be seen in Figure A1.

\begin{tabular}{|c|c|c|c|c|c|c|c|c|c|c|c|}
\hline Ref & Year & Country & Energy Type & Technique & Forecast & Other Input & MAPE $^{1 /}$ & $\mathbf{N}^{2 /}$ & Scale & \multicolumn{2}{|c|}{ Date Sample } \\
\hline [73] & 2006 & Australia & No Specific & ERNN; WT & Electricity Load & TM, HM, WS & 0.794 & 26,297 & Hours & 1999 & 2002 \\
\hline [74] & 2013 & Iran & Wind & PSO; ACO & Wind Power & TM, WS & 3.513 & 8736 & Hours & 2010 & 2011 \\
\hline [75] & 2008 & Iran & No Specific & ANN; EA & Peak Load & CI & 1.760 & 26,280 & Hours & 1997 & 1999 \\
\hline$[76]$ & 2008 & EEUU & No Specific & SVR; BT & Electricity Load & CI, TM, HM & 1.960 & 30,144 & Hours & 2001 & 2004 \\
\hline [77] & 2015 & Australia & No specific & ANN & Electrical power & CI & 3.710 & 70,080 & Half-Hour & 2006 & 2009 \\
\hline [78] & 2017 & UK & No Specific & PSO; ANN & Load Demand & CI, TM & 1.723 & 8760 & Hours & 2008 & 2008 \\
\hline [79] & 2016 & Algeria & No Specific & $\begin{array}{l}\text { HW-ES; KNN; WD; } \\
\text { Fuzzy-CM; ANFIS }\end{array}$ & Peak Electricity & $\mathrm{TM}$ & 2.796 & 1064 & Days & 2012 & 2014 \\
\hline [81] & 2017 & Poland & No Specific & ANN; PCA & Power Load & CI, TM & 1.235 & 26,280 & Hours & 2009 & 2012 \\
\hline [82] & 2018 & India & No Specific & ANN; PSO; GA & $\begin{array}{l}\text { Electricity } \\
\text { Demand }\end{array}$ & CPI, GDP & 0.220 & 25 & Years & 1991 & 2015 \\
\hline [83] & 2017 & UK & No Specific & ELM; Fuzzy & Electricity Load & CI, TM, DP & 1.435 & 43,852 & Hours & 2004 & 2008 \\
\hline [84] & 2019 & EEUU & Wind & NWP; WD; CNN & Wind Power & CI, TM, WS, DP & 2.550 & 26,280 & Hours & 2015 & 2017 \\
\hline [85] & 2008 & Iran & No Specific & BNN; MCM; Fuzzy & Load & CI, TM & 2.421 & 1460 & Days & 2004 & 2007 \\
\hline [27] & 2018 & Vietnam & No Specific & WT; ANFIS; COA & Electricity & $\begin{array}{l}\text { CI, TM, HM, PRS, } \\
\text { RFL, RT, WS }\end{array}$ & 4.330 & 132 & Months & 2003 & 2013 \\
\hline [86] & 2017 & UK & No Specific & ANN; JOA & Electricity Load & CI, TM, DP & 5.710 & 52,560 & Hours & 2004 & 2009 \\
\hline [6] & 2019 & Australia & No Specific & ANN; BOOT & Electricity & 57 Index & 5.290 & 4300 & $6 \mathrm{~h}$ & 2014 & 2017 \\
\hline [89] & 2019 & Uganda & No Specific & PSO; ABC & Electricity & POP, GDP, EP, NS & 1.306 & 17 & Years & 1990 & 2016 \\
\hline [90] & 2020 & Australia & Photovoltaic & WD; LSTM & Power & TM, HM, WS, HR & 1.868 & 213,984 & $5 \mathrm{~min}$ & 2014 & 2016 \\
\hline [91] & 2018 & Turkey & No Specific & ANFIS & Electrical Load & CI, TM & 8.869 & 8760 & Hours & 2017 & 2017 \\
\hline
\end{tabular}


Table 4. Hypothesis Test for Difference in Means. ${ }^{1 /}$ Levene Test ( $p$-value) ${ }^{2 /}$ test ( $p$-value).

\begin{tabular}{ccccc}
\hline Variable & Hypothesis $\left(\boldsymbol{H}_{\mathbf{0}}\right)$ & Homogeneity of Variance ${ }^{\mathbf{1} /}$ & Difference in Means $^{2 /}$ & $\begin{array}{c}\text { Effect Size } \\
\text { (Cohen's) }\end{array}$ \\
\hline Model & $\mu_{M L} \geq \mu_{M S C}$ & 0.00386 & 0.07252 & Small \\
Hybrid & $\mu_{Y e s} \geq \mu_{N o}$ & 0.09063 & 0.04321 & Small \\
Dependency & $\mu_{M u l t i} \geq \mu_{U n i}$ & 0.00125 & 0.00059 & Medium \\
\hline
\end{tabular}

In this sense, a summary of the documents found in the review with MAPEs and HAPs that base their models on ML with a hybrid approach and multivariate dependence is presented in the Table 3. When we analyzed these documents, we observed that there are common elements; for example, when building a word cloud from the abstracts, keywords and titles of these documents, we can identify that in $24 \%$ of the cases multiple scale decomposition and wavelet theory (WT) were mentioned.

The wavelet transform, including filtering and forecasting, has been suggest for detailed examination of the elements or structure of time series in several academic papers in recent years [73]. WT has been extensively implemented in electric power forecasting for decomposing electricity series into series with particular characteristics that can be predicted more accurately than the original time series [186-188].

\section{Case Study}

In this section, we propose a hybrid model to forecast the electric power by using a type of recurrent artificial neural network known as long short-term memory (LSTM), developed by [189]; we also implemented wavelet decomposition for the data preprocessing (WD-LSTM), as was used in [90]. We use the acronym WD-LSTM for the proposed hybrid model. The results were compared with those of traditional neural network models (LSTM), as was applied in [71,177] and with results of the lagged regression analysis as in [96].

The performance of this methods is demonstrated with a case study using an actual dataset collected from Chile (Table 5). The objective is to illustrated the approach that allows the electric power demand forecasting, in terms of its lagged values, identifying the type of model that tends to show better forecast accuracy.

Maximum daily and hourly electric power demand data over a diverse period were used (Table 5). Figure 9 shows that there is a regularity in electric power demand data. We observe a clear pattern based on the year and day of the week. The electric power demand also follows a group of patterns within any day and depending on the time of the day.

Table 5. Electric power demand object of forecasting.

\begin{tabular}{ccccccc}
\hline \multirow{2}{*}{ Type } & \multirow{2}{*}{ Variable } & Date & \multicolumn{3}{c}{ Set Size } \\
\cline { 5 - 7 } & & & Training & Validation & Test \\
\hline Local & Dmax & Maximum daily electricity demand $(M W)$. & $2006-2019$ & 2475 & 1516 & 1062 \\
Energy & Hed & Hourly electricity demand $(M W)$. & $2016-2020$ & 865 & 371 & 530 \\
\hline
\end{tabular}

The values of four performance evaluation indicators-RMSE: root mean square error, MAE: mean absolute error, $R^{2}$ : coefficient of determination, and MAPE: mean absolute percentage error-showed that the hybrid deep learning model (WD-LSTM) exhibits superior performance in both forecasting accuracy and stability. 

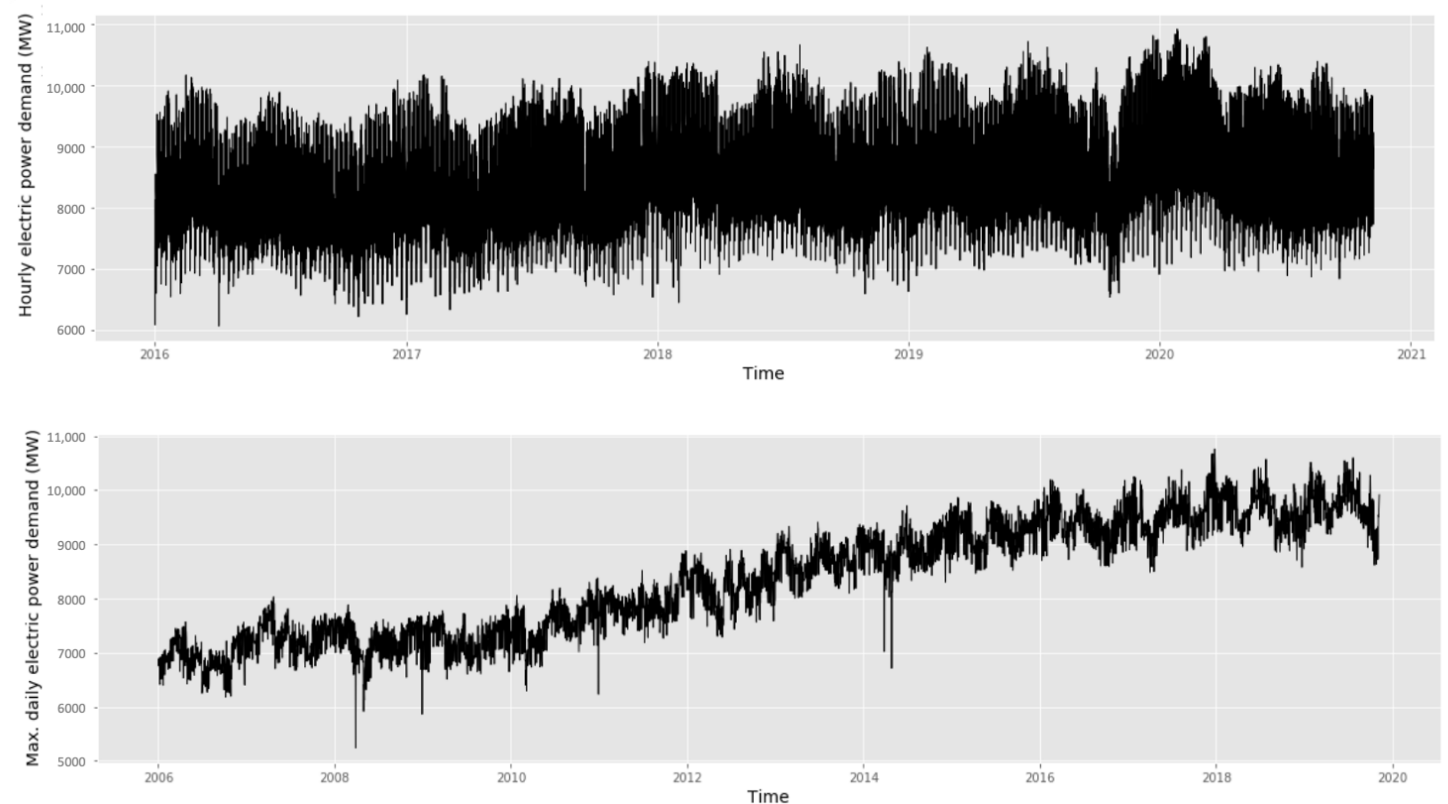

Figure 9. Electric power demand series (MW) in Chile.

Figures 10 and 11 provide the comparative hourly and daily-ahead performance results for three types of days (weekday, weekend, and all days). They likewise provide the performance evaluation results of regression, LSTM, and WD-LSTM applied to each dataset (training, validation, and test). The hybrid deep learning model (WD-LSTM) had the best performance of all forecasting models. The WD-LSTM method generated forecasting results with the lowest MAE, MAPE, and RMSE and with the higher $R^{2}$ in most cases. The results further reveal the robustness of the hybrid deep learning model. The superior accuracy of the hybrid model is primarily due to the deep learning framework comprising between two and four independent LSTM networks, which provide an effective means to approximate inherent invariant features and structures. In addition, the lowand high-frequency components exhibited in the electric power datasets can be better extracted by wavelet decomposition. Likewise, each LSTM network managed to focus more on capturing the linear and nonlinear relationships in the energy series, which could not be done with the lagged regression, at least in non-linear cases.
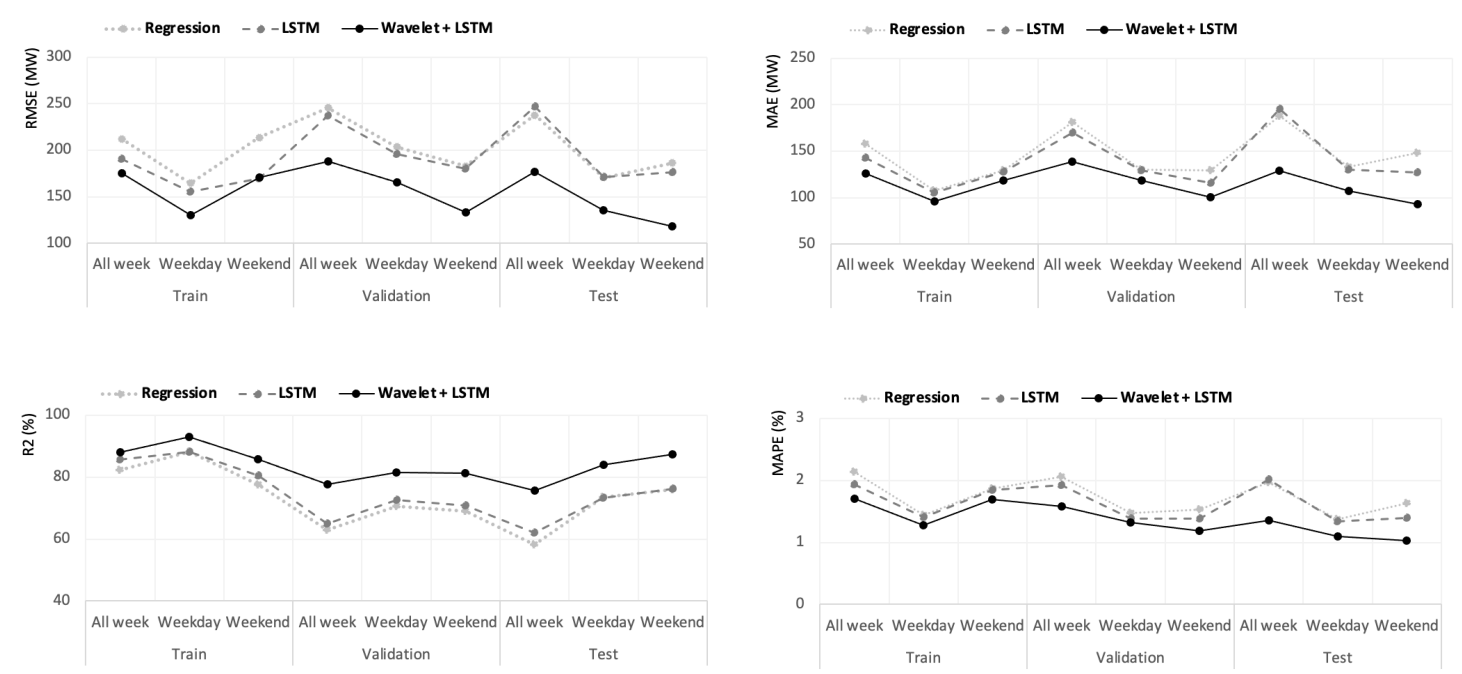

Figure 10. Performance evaluations of different methods for each type of day. 

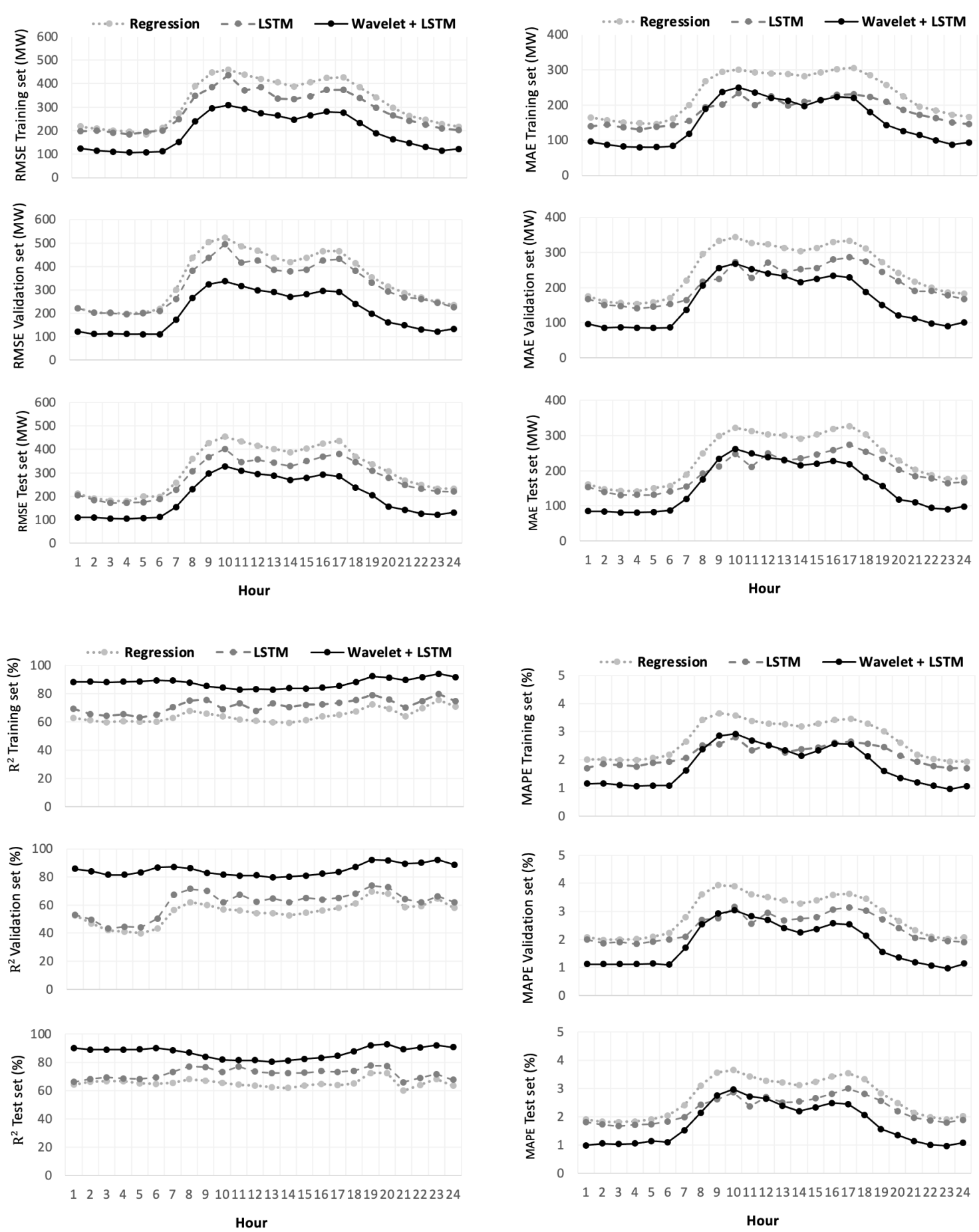

Figure 11. Performance evaluations of different methods for hour.

\section{Discussion and Conclusions}

This paper presented a systematic review of the forecasting models for electric power from the last 15 years based on ML and MSC techniques. We presented an in-depth analysis of the performance of electric power forecasting models and compared different forecasting models based on their MAPE values. A rigorous framework for comparing different classes of models was introduced, thus generating a reliable picture of the state-of-the-art models' accuracy of electric power forecasting. We were able to identify that a large number of techniques are being used and are aimed at forecasting electrical energy; the techniques with the greatest use are in the fields of ML and ANNs, followed by 
those that implement algorithms with fuzzy logic and RNNs, while in the MSC area, the use of ARIMA models and regression analysis predominates.

The results can be stratified from three perspectives. The forecasting models (I) from the hybrid class, (II) of multivariate dependency, and (III) based on the machine learning approach demonstrate the best performance for electric power forecasting. Regarding the hybrid models, it is highlighted that $24 \%$ of the adjustments with the greatest forecasting precision merged wavelet theory into their models. With regard to multivariate models, we were able to identify that those models that incorporate various sources of variability in their adjustment tend to have, on average, greater precision in their forecasts.

A case of study was presented, in which the implementation of MSC and ML models was compared; we found that the linear models, such as lagged regression, are relatively simple and cannot capture with precision the inherent nonlinear structure of the electric power time series, whereas the deep learning models implemented have a better performance.

Likewise, it was observed that when decomposing the series according to the type of day of electricity consumption (workday or weekend), the models tend to have better forecast accuracy and, in the same way, forecasting errors are minimized by reducing the time horizon (hourly).

Due to electric power systems' participation in the growing trend of environmental optimization around the world, a substantial increase in the contribution of diverse sources to the energy generation is observed. This trend brings about challenges in terms of electric power generation and distribution system operation, because the dimension and complexity of such advances, among other aspects, require the use of a computational intelligence systems that act as sources of data and deal with the control, management, and trading needs at the distribution level in an efficient and robust manner. In this sense, further research could deepen the understanding of the relationship between the type of energy, climate, preprocessing techniques, and performance of machine learning models under various normalized metrics of residuals.

Author Contributions: Conceptualization, E.V., H.A.-C. and R.S.; methodology, E.V., H.A-.C. and R.S.; software, E.V. and H.A.-C.; validation, all authors; writing —original draft preparation, E.V.; writing—review and editing, all authors; supervision, H.A.-C. All authors have read and agreed to the published version of the manuscript.

Funding: This research received internal funding form the Pontificia Universidad Católica de Valparaíso (PUCV).

Acknowledgments: We are grateful to the School of Informatic Engineering at Pontificia Universidad Católica de Valparaíso (PUCV) of Chile for the Scholarship Programme under which the first author is funded for her Doctoral study. Héctor Allende-Cid's work was funded by project $039.457 / 2020$ from VRIEA PUCV.

Conflicts of Interest: The authors declare no conflict of interest. The funders had no role in the design of the study; in the collection, analyses, or interpretation of data; in the writing of the manuscript; or in the decision to publish the results.

\section{Abbreviations}

The following abbreviations are used in this manuscript:

$\begin{array}{llll}\text { Nomenclature } & & & \text { GM } \\ \text { Artificial bee colony } & \text { ABC } & \text { Gray model } & \text { GDP } \\ \text { Ant Colony Optimization } & \text { ACO } & \text { Gross domestic product } & \text { HCM } \\ \text { Adaptive Neuro Fuzzy Inference System } & \text { ANFIS } & \text { Hybrid Monte Carlo } & \text { HM } \\ \text { Artificial Neural Network } & \text { ANN } & \text { Humidity } & \text { HR } \\ \text { Autoregressive Integrated Moving Aevrage } & \text { ARIMA } & \text { Horizontal Radiation } & \text { HW } \\ \text { Bayesian Clustering by Dynamics } & \text { BCD } & \text { Holt Winters } & \text { JOA } \\ \text { Bayesian neural network } & \text { BNN } & \text { Jaya optimization algorithm } & \text { KNN } \\ \text { Biogeography based optimization } & \text { BOA } & \text { K-nearest neighbors } & \text { LSTM } \\ \text { Back propagation } & \text { BP } & \text { Long short term memory } & \text { NS } \\ \text { Calendar information } & \text { CI } & \text { Number of subscribers } & \text { NWP } \\ \text { Convolution Neural Network } & \text { CNN } & \text { Numerical Weather Prediction } & \end{array}$


Cuckoo Search Algorithm

Consumer Price Index

Deep Belief Network

Dew point

Evolutionary Algorithm

Extreme learning machine

Electricity price

Elman Recurrent Neural Network

Exponential smoothing

Exports

Fuzzy Neural Network

Gaussian Process

Genetic algorithm

Generalized Additive Model

$\begin{array}{lll}\text { COA } & \text { Principal component analysis } & \text { PCA } \\ \text { CPI } & \text { Population } & \text { POP } \\ \text { DBN } & \text { Air pressure } & \text { PRS } \\ \text { DP } & \text { Particle Swarm Optimization } & \text { PSO } \\ \text { EA } & \text { Radial basis function network } & \text { RBF } \\ \text { ELM } & \text { Rainfall } & \text { RFL } \\ \text { EP } & \text { Rainy time } & \text { RT } \\ \text { ERNN } & \text { Recurrent Neural Network } & \text { RNN } \\ \text { ES } & \text { Regression Analysis } & \text { RA } \\ \text { EXP } & \text { Support Vector Regression } & \text { SVR } \\ \text { FNN } & \text { Temperature } & \text { TM } \\ \text { GP } & \text { Wind direction } & \text { WDD } \\ \text { GA } & \text { Wind speed } & \text { WS } \\ \text { GAM } & \text { Wavelet theory } & \text { WT }\end{array}$

\section{Appendix A}

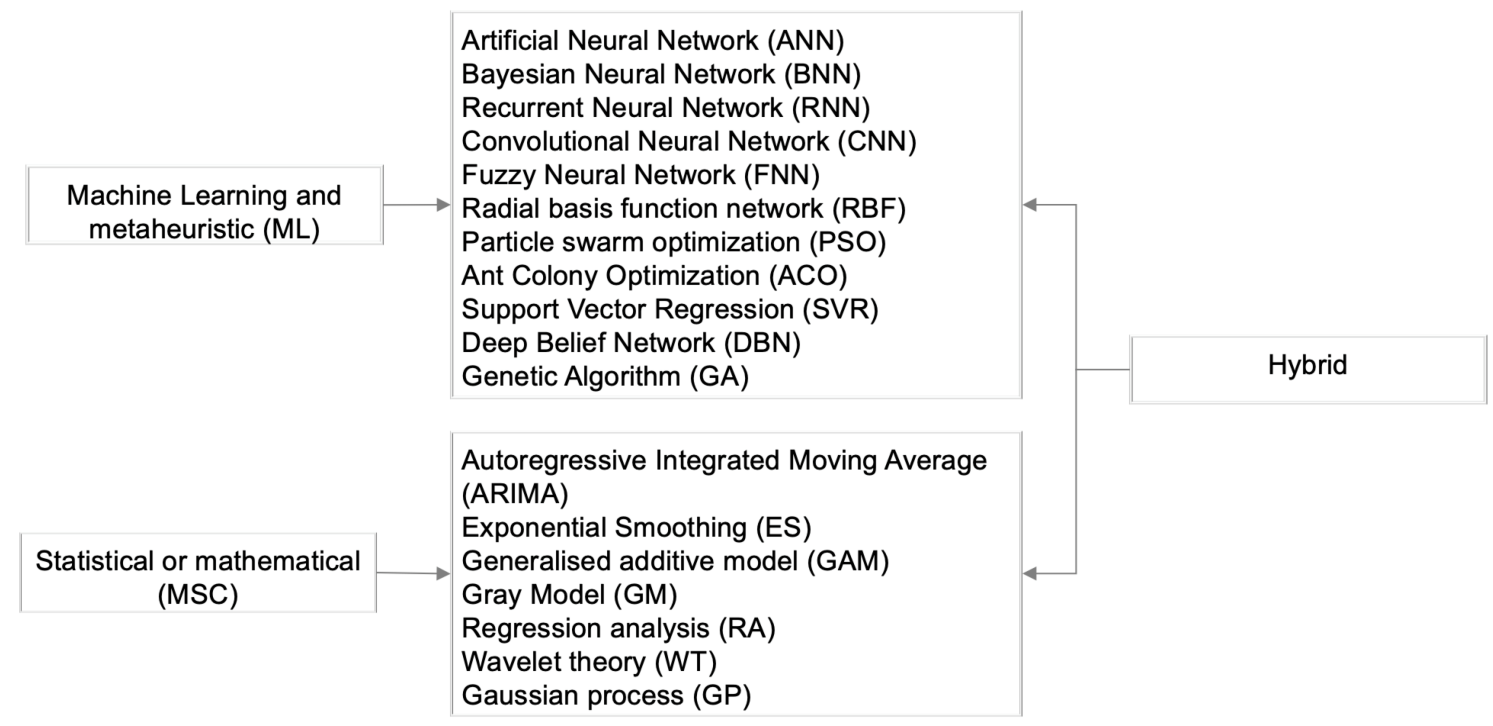

Figure A1. Classification of the forecasting models.

\section{References}

1. Taylor, J.W.; De Menezes, L.M.; McSharry, P.E. A comparison of univariate methods for forecasting electricity demand up to a day ahead. Int. J. Forecast. 2006, 22, 1-16. [CrossRef]

2. Banos, R.; Manzano-Agugliaro, F.; Montoya, F.; Gil, C.; Alcayde, A.; Gómez, J. Optimization methods applied to renewable and sustainable energy: A review. Renew. Sustain. Energy Rev. 2011, 15, 1753-1766. [CrossRef]

3. Sharma, A.; Kakkar, A. Forecasting daily global solar irradiance generation using machine learning. Renew. Sustain. Energy Rev. 2018, 82, 2254-2269. [CrossRef]

4. Li, J.; Ward, J.K.; Tong, J.; Collins, L.; Platt, G. Machine learning for solar irradiance forecasting of photovoltaic system. Renew. Energy 2016, 90, 542-553. [CrossRef]

5. Rahman, M.N.; Esmailpour, A.; Zhao, J. Machine learning with big data an efficient electricity generation forecasting system. Big Data Res. 2016, 5, 9-15. [CrossRef]

6. Al-Musaylh, M.S.; Deo, R.C.; Adamowski, J.F.; Li, Y. Short-term electricity demand forecasting using machine learning methods enriched with ground-based climate and ECMWF Reanalysis atmospheric predictors in southeast Queensland, Australia. Renew. Sustain. Energy Rev. 2019, 113, 109293. [CrossRef]

7. Kim, S.G.; Jung, J.Y.; Sim, M.K. A Two-Step Approach to Solar Power Generation Prediction Based on Weather Data Using Machine Learning. Sustainability 2019, 11, 1501. [CrossRef] 
8. Abedinia, O.; Raisz, D.; Amjady, N. Effective prediction model for Hungarian small-scale solar power output. IET Renew. Power Gener. 2017, 11, 1648-1658. [CrossRef]

9. Abuella, M.; Chowdhury, B. Improving combined solar power forecasts using estimated ramp rates: Data-driven post-processing approach. IET Renew. Power Gener. 2018, 12, 1127-1135. [CrossRef]

10. Yang, Y.; Chen, Y.; Wang, Y.; Li, C.; Li, L. Modelling a combined method based on ANFIS and neural network improved by DE algorithm: A case study for short-term electricity demand forecasting. Appl. Soft Comput. 2016, 49, 663-675. [CrossRef]

11. Fiot, J.B.; Dinuzzo, F. Electricity demand forecasting by multi-task learning. IEEE Trans. Smart Grid 2016, 9, 544-551. [CrossRef]

12. Wang, F.; Yu, Y.; Zhang, Z.; Li, J.; Zhen, Z.; Li, K. Wavelet decomposition and convolutional LSTM networks based improved deep learning model for solar irradiance forecasting. Appl. Sci. 2018, 8, 1286. [CrossRef]

13. Liu, Y.; Guan, L.; Hou, C.; Han, H.; Liu, Z.; Sun, Y.; Zheng, M. Wind Power Short-Term Prediction Based on LSTM and Discrete Wavelet Transform. Appl. Sci. 2019, 9, 1108. [CrossRef]

14. Jin, X.; Dong, Y.; Wu, J.; Wang, J. An improved combined forecasting method for electric power load based on autoregressive integrated moving average model. In Proceedings of the 2010 International Conference of Information Science and Management Engineering, Xi'an, China, 7-8 August 2010; Volume 2, pp. 476-480.

15. Sarkodie, S.A. Estimating Ghana's electricity consumption by 2030: An ARIMA forecast. Energy Sources Part B Econ. Plan. Policy 2017, 12, 936-944. [CrossRef]

16. Barzola-Monteses, J.; Mite-León, M.; Espinoza-Andaluz, M.; Gómez-Romero, J.; Fajardo, W. Time Series Analysis for Predicting Hydroelectric Power Production: The Ecuador Case. Sustainability 2019, 11, 6539. [CrossRef]

17. Filik, U.B.; Gerek, O.N.; Kurban, M. Hourly forecasting of long term electric energy demand using a novel modeling approach. In Proceedings of the 2009 Fourth International Conference on Innovative Computing, Information and Control (ICICIC), Kaohsiung, Taiwan, 7-9 December 2009; pp. 115-118.

18. Filik, Ü.B.; Gerek, Ö.N.; Kurban, M. A novel modeling approach for hourly forecasting of long-term electric energy demand. Energy Convers. Manag. 2011, 52, 199-211. [CrossRef]

19. Liang, J.; Liang, Y. Analysis and modeling for China's electricity demand forecasting based on a new mathematical hybrid method. Information 2017, 8, 33. [CrossRef]

20. Khan, A.R.; Mahmood, A.; Safdar, A.; Khan, Z.A.; Khan, N.A. Load forecasting, dynamic pricing and DSM in smart grid: A review. Renew. Sustain. Energy Rev. 2016, 54, 1311-1322. [CrossRef]

21. Mosavi, A.; Salimi, M.; Faizollahzadeh Ardabili, S.; Rabczuk, T.; Shamshirband, S.; Varkonyi-Koczy, A.R. State of the art of machine learning models in energy systems, a systematic review. Energies 2019, 12, 1301. [CrossRef]

22. Qasem, S.N.; Samadianfard, S.; Sadri Nahand, H.; Mosavi, A.; Shamshirband, S.; Chau, K.w. Estimating daily dew point temperature using machine learning algorithms. Water 2019, 11, 582. [CrossRef]

23. Kalogirou, S.A. Applications of artificial neural-networks for energy systems. Appl. Energy 2000, 67, 17-35. [CrossRef]

24. Voyant, C.; Notton, G.; Kalogirou, S.; Nivet, M.L.; Paoli, C.; Motte, F.; Fouilloy, A. Machine learning methods for solar radiation forecasting: A review. Renew. Energy 2017, 105, 569-582. [CrossRef]

25. Blaga, R.; Sabadus, A.; Stefu, N.; Dughir, C.; Paulescu, M.; Badescu, V. A current perspective on the accuracy of incoming solar energy forecasting. Prog. Energy Combust. Sci. 2019, 70, 119-144. [CrossRef]

26. Verdejo, H.; Awerkin, A.; Becker, C.; Olguin, G. Statistic linear parametric techniques for residential electric energy demand forecasting. A review and an implementation to Chile. Renew. Sustain. Energy Rev. 2017, 74, 512-521. [CrossRef]

27. Chen, J.F.; Do, Q.H.; Nguyen, T.V.A.; Doan, T.T.H. Forecasting monthly electricity demands by wavelet neuro-fuzzy system optimized by heuristic algorithms. Information 2018, 9, 51. [CrossRef]

28. Lewis, C.D. Industrial and Business Forecasting Methods: A Practical Guide to Exponential Smoothing and Curve Fitting; Butterworth-Heinemann: Oxford, UK, 1982.

29. Zhao, H.; Guo, S. An optimized grey model for annual power load forecasting. Energy 2016, 107, $272-286$. [CrossRef]

30. Ma, X.; Liu, Z. Application of a novel time-delayed polynomial grey model to predict the natural gas consumption in China. J. Comput. Appl. Math. 2017, 324, 17-24. [CrossRef] 
31. Lee, Y.S.; Tong, L.I. Forecasting energy consumption using a grey model improved by incorporating genetic programming. Energy Convers. Manag. 2011, 52, 147-152. [CrossRef]

32. Wang, J.; Du, P.; Lu, H.; Yang, W.; Niu, T. An improved grey model optimized by multi-objective ant lion optimization algorithm for annual electricity consumption forecasting. Appl. Soft Comput. 2018, 72, 321-337. [CrossRef]

33. Chang, P.C.; Fan, C.Y.; Lin, J.J. Monthly electricity demand forecasting based on a weighted evolving fuzzy neural network approach. Int. J. Electr. Power Energy Syst. 2011, 33, 17-27. [CrossRef]

34. Dedinec, A.; Filiposka, S.; Dedinec, A.; Kocarev, L. Deep belief network based electricity load forecasting: An analysis of Macedonian case. Energy 2016, 115, 1688-1700. [CrossRef]

35. Chang, G.; Lu, H.; Chang, Y.; Lee, Y. An improved neural network-based approach for short-term wind speed and power forecast. Renew. Energy 2017, 105, 301-311. [CrossRef]

36. Kaboli, S.H.A.; Selvaraj, J.; Rahim, N. Long-term electric energy consumption forecasting via artificial cooperative search algorithm. Energy 2016, 115, 857-871. [CrossRef]

37. El-Telbany, M.; El-Karmi, F. Short-term forecasting of Jordanian electricity demand using particle swarm optimization. Electr. Power Syst. Res. 2008, 78, 425-433. [CrossRef]

38. Ardakani, F.; Ardehali, M. Long-term electrical energy consumption forecasting for developing and developed economies based on different optimized models and historical data types. Energy 2014, 65, 452-461. [CrossRef]

39. Tsekouras, G.J.; Hatziargyriou, N.D.; Dialynas, E.N. An optimized adaptive neural network for annual midterm energy forecasting. IEEE Trans. Power Syst. 2006, 21, 385-391. [CrossRef]

40. López, M.; Valero, S.; Senabre, C.; Aparicio, J.; Gabaldon, A. Application of SOM neural networks to short-term load forecasting: The Spanish electricity market case study. Electr. Power Syst. Res. 2012, 91, 18-27. [CrossRef]

41. Setiawan, A.; Koprinska, I.; Agelidis, V.G. Very short-term electricity load demand forecasting using support vector regression. In Proceedings of the 2009 International Joint Conference on Neural Networks, Atlanta, GA, USA, 14-19 June 2009; pp. 2888-2894.

42. Al-Qahtani, F.H.; Crone, S.F. Multivariate k-nearest neighbour regression for time series data-A novel algorithm for forecasting UK electricity demand. In Proceedings of the 2013 International Joint Conference on Neural Networks (IJCNN), Dallas, TX, USA, 4-9 August 2013; pp. 1-8.

43. Guo, Z.; Zhou, K.; Zhang, X.; Yang, S. A deep learning model for short-term power load and probability density forecasting. Energy 2018, 160, 1186-1200. [CrossRef]

44. Ghanbari, A.; Naghavi, A.; Ghaderi, S.; Sabaghian, M. Artificial Neural Networks and regression approaches comparison for forecasting Iran's annual electricity load. In Proceedings of the 2009 International Conference on Power Engineering, Energy and Electrical Drives, Lisbon, Portugal, 18-20 March 2009; pp. 675-679.

45. Elias, C.N.; Hatziargyriou, N.D. An annual midterm energy forecasting model using fuzzy logic. IEEE Trans. Power Syst. 2009, 24, 469-478. [CrossRef]

46. Sahay, K.B.; Tripathi, M. Day ahead hourly load forecast of PJM electricity market and ISO New England market by using artificial neural network. In Proceedings of the ISGT 2014, Istanbul, Turkey, 15-18 October 2014; pp. 1-5.

47. Wang, J.; Zhou, Y.; Chen, X. Electricity load forecasting based on support vector machines and simulated annealing particle swarm optimization algorithm. In Proceedings of the 2007 IEEE International Conference on Automation and Logistics, Jinan, China, 18-21 August 2007; pp. 2836-2841.

48. Ehsan, R.M.; Simon, S.P.; Venkateswaran, P. Day-ahead forecasting of solar photovoltaic output power using multilayer perceptron. Neural Comput. Appl. 2017, 28, 3981-3992. [CrossRef]

49. De Leone, R.; Pietrini, M.; Giovannelli, A. Photovoltaic energy production forecast using support vector regression. Neural Comput. Appl. 2015, 26, 1955-1962. [CrossRef]

50. Vahabie, A.; Yousefi, M.R.; Araabi, B.; Lucas, C.; Barghinia, S.; Ansarimehr, P. Mutual information based input selection in neuro-fuzzy modeling for short term load forecasting of iran national power system. In Proceedings of the 2007 IEEE International Conference on Control and Automation, Guangzhou, China, 30 May-1 June 2007; pp. 2710-2715.

51. Ouyang, T.; He, Y.; Li, H.; Sun, Z.; Baek, S. Modeling and forecasting short-term power load with copula model and deep belief network. IEEE Trans. Emerg. Top. Comput. Intell. 2019, 3, 127-136. [CrossRef]

52. Barzamini, R.; Menhaj, M.; Khosravi, A.; Kamalvand, S. Short term load forecasting for iran national power system and its regions using multi layer perceptron and fuzzy inference systems. In Proceedings of the 2005 
IEEE International Joint Conference on Neural Networks, Montreal, QC, Canada, 31 July-4 August 2005; Volume 4, pp. 2619-2624.

53. Dilhani, M.S.; Jeenanunta, C. Effect of Neural Network structure for daily electricity load forecasting. In Proceedings of the 2017 Moratuwa Engineering Research Conference (MERCon), Moratuwa, Sri Lanka, 29-31 May 2017; pp. 419-424.

54. Chen, J.F.; Lo, S.K.; Do, Q.H. Forecasting monthly electricity demands: An application of neural networks trained by heuristic algorithms. Information 2017, 8, 31. [CrossRef]

55. Azadeh, A.; Ghaderi, S.F.; Sheikhalishahi, M.; Nokhandan, B.P. Optimization of short load forecasting in electricity market of Iran using artificial neural networks. Optim. Eng. 2014, 15, 485-508. [CrossRef]

56. Raza, M.Q.; Baharudin, Z.; Nallagownden, P. A comparative analysis of PSO and LM based NN short term load forecast with exogenous variables for smart power generation. In Proceedings of the 2014 5th International Conference on Intelligent and Advanced Systems (ICIAS), Kuala Lumpur, Malaysia, 3-5 June 2014; pp. 1-6.

57. Ishik, M.Y.; Göze, T.; Özcan, I.; Güngör, V.Ç.; Aydın, Z. Short term electricity load forecasting: A case study of electric utility market in Turkey. In Proceedings of the 2015 3rd International Istanbul Smart Grid Congress and Fair (ICSG), Istanbul, Turkey, 29-30 April 2015; pp. 1-5.

58. Sahay, K.B.; Kumar, N.; Tripathi, M. Short-term load forecasting of Ontario Electricity Market by considering the effect of temperature. In Proceedings of the 2014 6th IEEE Power India International Conference (PIICON), Delhi, India, 5-7 December 2014; pp. 1-6.

59. Azadeh, A.; Ghadrei, S.; Nokhandan, B.P. One day ahead load forecasting for electricity market of Iran by ANN. In Proceedings of the 2009 International Conference on Power Engineering, Energy and Electrical Drives, Lisbon, Portugal, 18-20 March 2009; pp. 670-674.

60. Akole, M.; Tyagi, B. Artificial neural network based short term load forecasting for restructured power system. In Proceedings of the 2009 International Conference on Power Systems, Kharagpur, India, 27-29 December 2009; pp. 1-7.

61. Chuang, F.K.; Hung, C.Y.; Chang, C.Y.; Kuo, K.C. Deploying arima and artificial neural networks models to predict energy consumption in Taiwan. Sens. Lett. 2013, 11, 2333-2340. [CrossRef]

62. Kavanagh, K.; Barrett, M.; Conlon, M. Short-term electricity load forecasting for the integrated single electricity market (I-SEM). In Proceedings of the 2017 52nd International Universities Power Engineering Conference (UPEC), Heraklion, Greece, 28-31 August 2017; pp. 1-7.

63. Sarkar, M.R.; Rabbani, M.G.; Khan, A.R.; Hossain, M.M. Electricity demand forecasting of Rajshahi City in Bangladesh using fuzzy linear regression model. In Proceedings of the 2015 International Conference on Electrical Engineering and Information Communication Technology (ICEEICT), Savar, Dhaka, Bangladesh, 21-23 May 2015; pp. 1-3.

64. Kelo, S.M.; Dudul, S.V. Development of an intelligent system for short-term electrical power load forecasting in Maharashtra state. In Proceedings of the 2008 Joint International Conference on Power System Technology and IEEE Power India Conference, New Delhi, India, 12-15 October 2008; pp. 1-8.

65. Gireeshma, K.; Atla, C.R.; Rao, K.L. New Correlation Technique for RE Power Forecasting using Neural Networks. In Proceedings of the 2019 Fifth International Conference on Electrical Energy Systems (ICEES), Chennai, India, 21-22 February 2019; pp. 1-6.

66. Barzamini, R.; Menhaj, M.; Kamalvand, S.; Tajbakhsh, A. Short term load forecasting of Iran national power system using artificial neural network generation two. In Proceedings of the 2005 IEEE Russia Power Tech, St. Petersburg, Russia, 27-30 June 2005; pp. 1-5.

67. Viet, D.T.; Van Phuong, V.; Duong, M.Q.; Kies, A.; Schyska, B.U.; Wu, Y.K. A Short-Term Wind Power Forecasting Tool for Vietnamese Wind Farms and Electricity Market. In Proceedings of the 2018 4th International Conference on Green Technology and Sustainable Development (GTSD), Ho Chi Minh City, Vietnam, 23-24 November 2018; pp. 130-135.

68. Sakunthala, K.; Iniyan, S.; Mahalingam, S. Forecasting energy consumption in Tamil Nadu using hybrid heuristic based regression model. Therm. Sci. 2019, 23, 2885-2894. [CrossRef]

69. Siridhipakul, C.; Vateekul, P. Multi-step Power Consumption Forecasting in Thailand Using Dual-Stage Attentional LSTM. In Proceedings of the 2019 11th International Conference on Information Technology and Electrical Engineering (ICITEE), Pattaya, Thailand, 10-11 October 2019; pp. 1-6. 
70. Tanidir, Ö.; Tör, O. Accuracy of ANN based day-ahead load forecasting in Turkish power system: Degrading and improving factors. Neural Netw. World 2015, 25, 443. [CrossRef]

71. Liu, J.; Wang, X.; Zhao, Y.; Dong, B.; Lu, K.; Wang, R. Heating Load Forecasting for Combined Heat and Power Plants Via Strand-Based LSTM. IEEE Access 2020, 8, 33360-33369. [CrossRef]

72. Chen, S.; Huang, J. Forecasting China's primary energy demand based on an improved AI model. Chin. J. Popul. Resour. Environ. 2018, 16, 36-48. [CrossRef]

73. Benaouda, D.; Murtagh, F.; Starck, J.L.; Renaud, O. Wavelet-based nonlinear multiscale decomposition model for electricity load forecasting. Neurocomputing 2006, 70, 139-154. [CrossRef]

74. Rahmani, R.; Yusof, R.; Seyedmahmoudian, M.; Mekhilef, S. Hybrid technique of ant colony and particle swarm optimization for short term wind energy forecasting. J. Wind. Eng. Ind. Aerodyn. 2013, 123, 163-170. [CrossRef]

75. Amjady, N.; Keynia, F. Mid-term load forecasting of power systems by a new prediction method. Energy Convers. Manag. 2008, 49, 2678-2687. [CrossRef]

76. Fan, S.; Chen, L.; Lee, W.J. Machine learning based switching model for electricity load forecasting. Energy Convers. Manag. 2008, 49, 1331-1344. [CrossRef]

77. Xiao, L.; Wang, J.; Yang, X.; Xiao, L. A hybrid model based on data preprocessing for electrical power forecasting. Int. J. Electr. Power Energy Syst. 2015, 64, 311-327. [CrossRef]

78. Raza, M.Q.; Nadarajah, M.; Hung, D.Q.; Baharudin, Z. An intelligent hybrid short-term load forecasting model for smart power grids. Sustain. Cities Soc. 2017, 31, 264-275. [CrossRef]

79. Laouafi, A.; Mordjaoui, M.; Laouafi, F.; Boukelia, T.E. Daily peak electricity demand forecasting based on an adaptive hybrid two-stage methodology. Int. J. Electr. Power Energy Syst. 2016, 77, 136-144. [CrossRef]

80. Ghanbari, A.; Ghaderi, S.F.; Azadeh, M.A. Adaptive Neuro-Fuzzy Inference System vs. Regression based approaches for annual electricity load forecasting. In Proceedings of the 2010 2nd International Conference on Computer and Automation Engineering (ICCAE), Singapore, 26-28 February 2010; Volume 5, pp. $26-30$.

81. Brodowski, S.; Bielecki, A.; Filocha, M. A hybrid system for forecasting 24-h power load profile for Polish electric grid. Appl. Soft Comput. 2017, 58, 527-539. [CrossRef]

82. Anand, A.; Suganthi, L. Hybrid GA-PSO optimization of artificial neural network for forecasting electricity demand. Energies 2018, 11, 728. [CrossRef]

83. Yeom, C.U.; Kwak, K.C. Short-term electricity-load forecasting using a TSK-based extreme learning machine with knowledge representation. Energies 2017, 10, 1613. [CrossRef]

84. Mujeeb, S.; Alghamdi, T.A.; Ullah, S.; Fatima, A.; Javaid, N.; Saba, T. Exploiting Deep Learning for Wind Power Forecasting Based on Big Data Analytics. Appl. Sci. 2019, 9, 4417. [CrossRef]

85. Barghinia, S.; Kamankesh, S.; Mahdavi, N.; Vahabie, A.; Gorji, A. A combination method for short term load forecasting used in Iran electricity market by NeuroFuzzy, Bayesian and finding similar days methods. In Proceedings of the 2008 5th International Conference on the European Electricity Market, Lisbon, Portugal, 28-30 May 2008; pp. 1-6.

86. Singh, P.; Mishra, K.; Dwivedi, P. Enhanced hybrid model for electricity load forecast through artificial neural network and Jaya algorithm. In Proceedings of the 2017 International Conference on Intelligent Computing and Control Systems (ICICCS), Madurai, India, 15-16 June 2017; pp. 115-120.

87. Kumaran, J.; Ravi, G. Long-term sector-wise electrical energy forecasting using artificial neural network and biogeography-based optimization. Electr. Power Compon. Syst. 2015, 43, 1225-1235. [CrossRef]

88. Zhou, J.; Xu, X.; Huo, X.; Li, Y. Forecasting models for wind power using extreme-point symmetric mode decomposition and artificial neural networks. Sustainability 2019, 11, 650. [CrossRef]

89. Kasule, A.; Ayan, K. Forecasting Uganda's net electricity consumption using a hybrid PSO-ABC Algorithm. Arab. J. Sci. Eng. 2019, 44, 3021-3031. [CrossRef]

90. Li, P.; Zhou, K.; Lu, X.; Yang, S. A hybrid deep learning model for short-term PV power forecasting. Appl. Energy 2020, 259, 114216. [CrossRef]

91. Kaysal, A.; Köroglu, S.; Oguz, Y.; Kaysal, K. Artificial Neural Networks and Adaptive Neuro-Fuzzy Inference Systems Approaches to Forecast the Electricity Data for Load Demand, an Analysis of Dinar District Case. In Proceedings of the 2018 2nd International Symposium on Multidisciplinary Studies and Innovative Technologies (ISMSIT), Ankara, Turkey, 19-21 October 2018; pp. 1-6.

92. Soares, L.J.; Medeiros, M.C. Modeling and forecasting short-term electricity load: A comparison of methods with an application to Brazilian data. Int. J. Forecast. 2008, 24, 630-644. [CrossRef] 
93. Almeshaiei, E.; Soltan, H. A methodology for electric power load forecasting. Alex. Eng. J. 2011, 50, 137-144. [CrossRef]

94. Hamzacebi, C.; Es, H.A. Forecasting the annual electricity consumption of Turkey using an optimized grey model. Energy 2014, 70, 165-171. [CrossRef]

95. Zhao, W.; Wang, J.; Lu, H. Combining forecasts of electricity consumption in China with time-varying weights updated by a high-order Markov chain model. Omega 2014, 45, 80-91. [CrossRef]

96. Wang, C.h.; Grozev, G.; Seo, S. Decomposition and statistical analysis for regional electricity demand forecasting. Energy 2012, 41, 313-325. [CrossRef]

97. Yukseltan, E.; Yucekaya, A.; Bilge, A.H. Forecasting electricity demand for Turkey: Modeling periodic variations and demand segregation. Appl. Energy 2017, 193, 287-296. [CrossRef]

98. Koprinska, I.; Rana, M.; Agelidis, V.G. Yearly and seasonal models for electricity load forecasting. In Proceedings of the 2011 International Joint Conference on Neural Networks, San Jose, CA, USA, 31 July-5 August 2011; pp. 1474-1481.

99. Rallapalli, S.R.; Ghosh, S. Forecasting monthly peak demand of electricity in India-A critique. Energy Policy 2012, 45, 516-520. [CrossRef]

100. Damrongkulkamjorn, P.; Churueang, P. Monthly energy forecasting using decomposition method with application of seasonal ARIMA. In Proceedings of the 2005 International Power Engineering Conference, Singapore, 29 November-2 December 2005; pp. 1-229.

101. Alamaniotis, M.; Bargiotas, D.; Tsoukalas, L.H. Towards smart energy systems: Application of kernel machine regression for medium term electricity load forecasting. SpringerPlus 2016, 5, 58. [CrossRef] [PubMed]

102. Koprinska, I.; Sood, R.; Agelidis, V. Variable selection for five-minute ahead electricity load forecasting. In Proceedings of the 2010 20th International Conference on Pattern Recognition, Istanbul, Turkey, 23-26 August 2010; pp. 2901-2904.

103. He, H.; Liu, T.; Chen, R.; Xiao, Y.; Yang, J. High frequency short-term demand forecasting model for distribution power grid based on ARIMA. In Proceedings of the 2012 IEEE International Conference on Computer Science and Automation Engineering (CSAE), Zhangjiajie, China, 25-27 May 2012; Volume 3, pp. 293-297.

104. An, Y.; Zhou, Y.; Li, R. Forecasting India's Electricity Demand Using a Range of Probabilistic Methods. Energies 2019, 12, 2574. [CrossRef]

105. Kantanantha, N.; Runsewa, S. Forecasting of electricity demand to reduce the inventory cost of imported coal. In Proceedings of the 2017 4th International Conference on Industrial Engineering and Applications (ICIEA), Nagoya, Japan, 21-23 April 2017; pp. 336-340.

106. Chen, H.; Li, F.; Wang, Y. Component GARCH-M type models for wind power forecasting. In Proceedings of the 2015 IEEE Power \& Energy Society General Meeting, Denver, CO, USA, 26-30 July 2015; pp. 1-5.

107. Kusakci, A.O.; Ayvaz, B. Electrical energy consumption forecasting for Turkey using grey forecasting technics with rolling mechanism. In Proceedings of the 2015 2nd International Conference on Knowledge-Based Engineering and Innovation (KBEI), Tehran, Iran, 5-6 November 2015; pp. 8-13.

108. González-Romera, E.; Jaramillo-Morán, M.; Carmona-Fernández, D. Monthly electric energy demand forecasting with neural networks and Fourier series. Energy Convers. Manag. 2008, 49, 3135-3142. [CrossRef]

109. Cao, G.; Wu, L. Support vector regression with fruit fly optimization algorithm for seasonal electricity consumption forecasting. Energy 2016, 115, 734-745. [CrossRef]

110. Li, C.; Li, S.; Liu, Y. A least squares support vector machine model optimized by moth-flame optimization algorithm for annual power load forecasting. Appl. Intell. 2016, 45, 1166-1178. [CrossRef]

111. Koprinska, I.; Rana, M.; Troncoso, A.; Martínez-Álvarez, F. Combining pattern sequence similarity with neural networks for forecasting electricity demand time series. In Proceedings of the 2013 International Joint Conference on Neural Networks (IJCNN), Dallas, TX, USA, 4-9 August 2013; pp. 1-8.

112. Al-Musaylh, M.S.; Deo, R.C.; Li, Y.; Adamowski, J.F. Two-phase particle swarm optimized-support vector regression hybrid model integrated with improved empirical mode decomposition with adaptive noise for multiple-horizon electricity demand forecasting. Appl. Energy 2018, 217, 422-439. [CrossRef]

113. Puspitasari, I.; Akbar, M.S.; Lee, M.H. Two-level seasonal model based on hybrid ARIMA-ANFIS for forecasting short-term electricity load in Indonesia. In Proceedings of the 2012 International Conference on Statistics in Science, Business and Engineering (ICSSBE), Langkawi, Kedah, Malaysia, 10-12 September 2012; pp. 1-5. 
114. Li, W.; Yang, X.; Li, H.; Su, L. Hybrid forecasting approach based on GRNN neural network and SVR machine for electricity demand forecasting. Energies 2017, 10, 44. [CrossRef]

115. Benaouda, D.; Murtagh, F. Electricity load forecast using neural network trained from wavelet-transformed data. In Proceedings of the 2006 IEEE International Conference on Engineering of Intelligent Systems, Islamabad, Pakistan, 22-23 April 2006; pp. 1-6.

116. Saroha, S.; Aggarwal, S. Wind power forecasting using wavelet transforms and neural networks with tapped delay. CSEE J. Power Energy Syst. 2018, 4, 197-209. [CrossRef]

117. Ni, K.; Wang, J.; Tang, G.; Wei, D. Research and Application of a Novel Hybrid Model Based on a Deep Neural Network for Electricity Load Forecasting: A Case Study in Australia. Energies 2019, 12, 2467. [CrossRef]

118. Jadidi, A.; Menezes, R.; de Souza, N.; de Castro Lima, A.C. Short-Term Electric Power Demand Forecasting Using NSGA II-ANFIS Model. Energies 2019, 12, 1891. [CrossRef]

119. Panapakidis, I.P.; Christoforidis, G.C.; Asimopoulos, N.; Dagoumas, A.S. Combining wavelet transform and support vector regression model for day-ahead peak load forecasting in the Greek power system. In Proceedings of the 2017 IEEE International Conference on Environment and Electrical Engineering and 2017 IEEE Industrial and Commercial Power Systems Europe (EEEIC/I\&CPS Europe), Milan, Italy, 6-9 June 2017; pp. 1-6.

120. Jiang, W.; Wu, X.; Gong, Y.; Yu, W.; Zhong, X. Holt-Winters smoothing enhanced by fruit fly optimization algorithm to forecast monthly electricity consumption. Energy 2020, 193, 116779. [CrossRef]

121. Sulandari, W.; Lee, M.H.; Rodrigues, P.C. Indonesian electricity load forecasting using singular spectrum analysis, fuzzy systems and neural networks. Energy 2020, 190, 116408. [CrossRef]

122. Laouafi, A.; Mordjaoui, M.; Medoued, A.; Boukelia, T.E.; Ganouche, A. Wind power forecasting approach using neuro-fuzzy system combined with wavelet packet decomposition, data preprocessing, and forecast combination framework. Wind Eng. 2017, 41, 235-244. [CrossRef]

123. Pao, H.T. Forecast of electricity consumption and economic growth in Taiwan by state space modeling. Energy 2009, 34, 1779-1791. [CrossRef]

124. Vu, D.H.; Muttaqi, K.M.; Agalgaonkar, A. A variance inflation factor and backward elimination based robust regression model for forecasting monthly electricity demand using climatic variables. Appl. Energy 2015, 140, 385-394. [CrossRef]

125. Tsekouras, G.; Dialynas, E.; Hatziargyriou, N.; Kavatza, S. A non-linear multivariable regression model for midterm energy forecasting of power systems. Electr. Power Syst. Res. 2007, 77, 1560-1568. [CrossRef]

126. Clements, A.E.; Hurn, A.; Li, Z. Forecasting day-ahead electricity load using a multiple equation time series approach. Eur. J. Oper. Res. 2016, 251, 522-530. [CrossRef]

127. Kim, M.S. Modeling special-day effects for forecasting intraday electricity demand. Eur. J. Oper. Res. 2013, 230, 170-180. [CrossRef]

128. Shang, H.L. Functional time series approach for forecasting very short-term electricity demand. J. Appl. Stat. 2013, 40, 152-168. [CrossRef]

129. Bessec, M.; Fouquau, J. Short-run electricity load forecasting with combinations of stationary wavelet transforms. Eur. J. Oper. Res. 2018, 264, 149-164. [CrossRef]

130. Chui, F.; Elkamel, A.; Surit, R.; Croiset, E.; Douglas, P. Long-term electricity demand forecasting for power system planning using economic, demographic and climatic variables. Eur. J. Ind. Eng. 2009, 3, 277-304. [CrossRef]

131. Truong, N.V.; Wang, L.; Wong, P.K. Modelling and short-term forecasting of daily peak power demand in Victoria using two-dimensional wavelet based SDP models. Int. J. Electr. Power Energy Syst. 2008, 30, 511-518. [CrossRef]

132. Mestekemper, T.; Kauermann, G.; Smith, M.S. A comparison of periodic autoregressive and dynamic factor models in intraday energy demand forecasting. Int. J. Forecast. 2013, 29, 1-12. [CrossRef]

133. Massidda, L.; Marrocu, M. Use of Multilinear Adaptive Regression Splines and numerical weather prediction to forecast the power output of a PV plant in Borkum, Germany. Sol. Energy 2017, 146, 141-149. [CrossRef]

134. Duan, L.; Niu, D.; Gu, Z. Long and medium term power load forecasting with multi-level recursive regression analysis. In Proceedings of the 2008 Second International Symposium on Intelligent Information Technology Application, Washington, DC, USA, 20-22 December 2008; Volume 1, pp. 514-518. 
135. Guo, H.; Chen, Q.; Xia, Q.; Kang, C.; Zhang, X. A monthly electricity consumption forecasting method based on vector error correction model and self-adaptive screening method. Int. J. Electr. Power Energy Syst. 2018, 95, 427-439. [CrossRef]

136. Elamin, N.; Fukushige, M. Modeling and forecasting hourly electricity demand by SARIMAX with interactions. Energy 2018, 165, 257-268. [CrossRef]

137. Sigauke, C. Forecasting medium-term electricity demand in a South African electric power supply system. J. Energy S. Afr. 2017, 28, 54-67. [CrossRef]

138. Tanrisever, F.; Derinkuyu, K.; Heeren, M. Forecasting electricity infeed for distribution system networks: An analysis of the Dutch case. Energy 2013, 58, 247-257. [CrossRef]

139. Bernardi, M.; Petrella, L. Multiple seasonal cycles forecasting model: The Italian electricity demand. Stat. Methods Appl. 2015, 24, 671-695. [CrossRef]

140. Angelopoulos, D.; Psarras, J.; Siskos, Y. Long-term electricity demand forecasting via ordinal regression analysis: The case of Greece. In Proceedings of the 2017 IEEE Manchester PowerTech, Manchester, UK, 18-22 June 2017; pp. 1-6.

141. Bermúdez, J.D. Exponential smoothing with covariates applied to electricity demand forecast. Eur. J. Ind. Eng. 2013, 7, 333-349. [CrossRef]

142. Sigauke, C.; Chikobvu, D. Peak electricity demand forecasting using time series regression models: An application to South African data. J. Stat. Manag. Syst. 2016, 19, 567-586. [CrossRef]

143. Angelopoulos, D.; Siskos, Y.; Psarras, J. Disaggregating time series on multiple criteria for robust forecasting: The case of long-term electricity demand in Greece. Eur. J. Oper. Res. 2019, 275, 252-265. [CrossRef]

144. Kumru, M.; Kumru, P.Y. Calendar-based short-term forecasting of daily average electricity demand. In Proceedings of the 2015 International Conference on Industrial Engineering and Operations Management (IEOM), Hyatt Regency, Dubai, 3-5 March 2015; pp. 1-5.

145. He, Y.; Zheng, Y.; Xu, Q. Forecasting energy consumption in Anhui province of China through two Box-Cox transformation quantile regression probability density methods. Measurement 2019, 136, 579-593. [CrossRef]

146. İlseven, E.; Göl, M. Medium-term electricity demand forecasting based on MARS. In Proceedings of the 2017 IEEE PES Innovative Smart Grid Technologies Conference Europe (ISGT-Europe), Torino, Italy, 26-29 September 2017; pp. 1-6.

147. Lebotsa, M.E.; Sigauke, C.; Bere, A.; Fildes, R.; Boylan, J.E. Short term electricity demand forecasting using partially linear additive quantile regression with an application to the unit commitment problem. Appl. Energy 2018, 222, 104-118. [CrossRef]

148. Cho, H.; Goude, Y.; Brossat, X.; Yao, Q. Modeling and forecasting daily electricity load curves: A hybrid approach. J. Am. Stat. Assoc. 2013, 108, 7-21. [CrossRef]

149. Sigauke, C.; Chikobvu, D. Prediction of daily peak electricity demand in South Africa using volatility forecasting models. Energy Econ. 2011, 33, 882-888. [CrossRef]

150. Li, S.; Yang, X.; Li, R. Forecasting China's coal power installed capacity: A comparison of MGM, ARIMA, GM-ARIMA, and NMGM models. Sustainability 2018, 10, 506. [CrossRef]

151. He, Y.; Zheng, Y. Short-term power load probability density forecasting based on Yeo-Johnson transformation quantile regression and Gaussian kernel function. Energy 2018, 154, 143-156. [CrossRef]

152. Cheng, C.T.; Miao, S.M.; Luo, B.; Sun, Y.J. Forecasting monthly energy production of small hydropower plants in ungauged basins using grey model and improved seasonal index. J. Hydroinform. 2017, 19, 993-1008. [CrossRef]

153. Monteiro, C.; Ramirez-Rosado, I.J.; Fernandez-Jimenez, L.A. Short-term forecasting model for electric power production of small-hydro power plants. Renew. Energy 2013, 50, 387-394. [CrossRef]

154. Moreno, J. Hydraulic plant generation forecasting in Colombian power market using ANFIS. Energy Econ. 2009, 31, 450-455. [CrossRef]

155. Perez-Mora, N.; Canals, V.; Martinez-Moll, V. Short-term Spanish aggregated solar energy forecast. In International Work-Conference on Artificial Neural Networks; Springer: Berlin/Heidelberg, Germany, 2015; pp. 307-319.

156. Lahouar, A.; Mejri, A.; Slama, J.B.H. Importance based selection method for day-ahead photovoltaic power forecast using random forests. In Proceedings of the 2017 International Conference on Green Energy Conversion Systems (GECS), Hammamet, Tunisia, 23-25 March 2017; pp. 1-7. 
157. Jung, Y.; Jung, J.; Kim, B.; Han, S. Long short-term memory recurrent neural network for modeling temporal patterns in long-term power forecasting for solar PV facilities: Case study of South Korea. J. Clean. Prod. 2020, 250, 119476. [CrossRef]

158. Lahouar, A.; Slama, J.B.H. Hour-ahead wind power forecast based on random forests. Renew. Energy 2017, 109, 529-541. [CrossRef]

159. Rana, M.; Koprinska, I.; Troncoso, A. Forecasting hourly electricity load profile using neural networks. In Proceedings of the 2014 International Joint Conference on Neural Networks (IJCNN), Beijing, China, 6-11 July 2014; pp. 824-831.

160. Lu, S.L. Integrating heuristic time series with modified grey forecasting for renewable energy in Taiwan. Renew. Energy 2019, 133, 1436-1444. [CrossRef]

161. Colombo, T.; Koprinska, I.; Panella, M. Maximum Length Weighted Nearest Neighbor approach for electricity load forecasting. In Proceedings of the 2015 International Joint Conference on Neural Networks (IJCNN), Killarney, Ireland, 12-17 July 2015; pp. 1-8.

162. Wang, C.H.; Lin, K.P.; Lu, Y.M.; Wu, C.F. Deep Belief Network with Seasonal Decomposition for Solar Power Output Forecasting. Int. J. Reliab. Qual. Saf. Eng. 2019, 26, 1950029. [CrossRef]

163. Lahouar, A. Gaussian Process Based Method for Point and Probabilistic Short-Term Wind Power Forecast. In International Conference on the Sciences of Electronics, Technologies of Information and Telecommunications; Springer: Berlin/Heidelberg, Germany, 2018; pp. 134-147.

164. da Silva Fonseca, J.G., Jr.; Oozeki, T.; Takashima, T.; Koshimizu, G.; Uchida, Y.; Ogimoto, K. Use of support vector regression and numerically predicted cloudiness to forecast power output of a photovoltaic power plant in Kitakyushu, Japan. Prog. Photovoltaics Res. Appl. 2012, 20, 874-882. [CrossRef]

165. Koprinska, I.; Rana, M.; Agelidis, V.G. Correlation and instance based feature selection for electricity load forecasting. Knowl. Based Syst. 2015, 82, 29-40. [CrossRef]

166. Taylor, J.W. An evaluation of methods for very short-term load forecasting using minute-by-minute British data. Int. J. Forecast. 2008, 24, 645-658. [CrossRef]

167. Taylor, J.W. Short-term load forecasting with exponentially weighted methods. IEEE Trans. Power Syst. 2012, 27, 458-464. [CrossRef]

168. Lotufo, A.; Minussi, C. Electric power systems load forecasting: A survey. In Proceedings of the PowerTech Budapest 99. Abstract Records., (Cat. No. 99EX376), Budapest, Hungary, 29 August-2 September 1999; p. 36.

169. Shumway, R.H.; Stoffer, D.S. Time Series Analysis and Its Applications: With R Examples; Springer: Berlin/Heidelberg, Germany, 2017.

170. Whittle, P. Hypothesis Testing in Time Series Analysis; Almqvist \& Wiksells boktr.: Stockholm, Sweden, 1951; Volume 4.

171. Box, G.E.; Jenkins, G.M.; Reinsel, G.C. Time Series Analysis: Forecasting and Control; John Wiley \& Sons: Hoboken, NJ, USA, 2011; Volume 734.

172. Makridakis, S.; Spiliotis, E.; Assimakopoulos, V. Statistical and Machine Learning forecasting methods: Concerns and ways forward. PLoS ONE 2018, 13, e0194889. [CrossRef] [PubMed]

173. Murphy, K.P. Machine Learning: A Probabilistic Perspective; MIT press: Cambridge, MA, USA, 2012.

174. Tosh, C.R.; Ruxton, G.D. Modelling Perception with Artificial Neural Networks; Cambridge University Press: Cambridge, UK, 2010.

175. Azadeh, A.; Ghaderi, S.; Sohrabkhani, S. A simulated-based neural network algorithm for forecasting electrical energy consumption in Iran. Energy Policy 2008, 36, 2637-2644. [CrossRef]

176. Hamzaçebi, C.; Es, H.A.; Çakmak, R. Forecasting of Turkey's monthly electricity demand by seasonal artificial neural network. Neural Comput. Appl. 2017, 31, 2217-2231. [CrossRef]

177. Ma, J.; Oppong, A.; Acheampong, K.N.; Abruquah, L.A. Forecasting renewable energy consumption under zero assumptions. Sustainability 2018, 10, 576. [CrossRef]

178. Li, G.; Wang, H.; Zhang, S.; Xin, J.; Liu, H. Recurrent neural networks based photovoltaic power forecasting approach. Energies 2019, 12, 2538. [CrossRef]

179. Tzafestas, S.G. Introduction to Mobile Robot Control; Elsevier: Amsterdam, The Netherlands, 2013.

180. Efendi, R.; Ismail, Z.; Deris, M.M. A new linguistic out-sample approach of fuzzy time series for daily forecasting of Malaysian electricity load demand. Appl. Soft Comput. 2015, 28, 422-430. [CrossRef] 
181. Marwala, L.; Twala, B. Forecasting electricity consumption in South Africa: ARMA, neural networks and neuro-fuzzy systems. In Proceedings of the 2014 International Joint Conference on Neural Networks (IJCNN), Beijing, China, 6-11 July 2014; pp. 3049-3055.

182. Rebala, G.; Ravi, A.; Churiwala, S. An Introduction to Machine Learning; Springer: Berlin/Heidelberg, Germany, 2019.

183. Al-Musaylh, M.S.; Deo, R.C.; Adamowski, J.F.; Li, Y. Short-term electricity demand forecasting with MARS, SVR and ARIMA models using aggregated demand data in Queensland, Australia. Adv. Eng. Inform. 2018, 35, 1-16. [CrossRef]

184. Lin, K.P.; Pai, P.F. Solar power output forecasting using evolutionary seasonal decomposition least-square support vector regression. J. Clean. Prod. 2016, 134, 456-462. [CrossRef]

185. Sood, R.; Koprinska, I.; Agelidis, V.G. Electricity load forecasting based on autocorrelation analysis. In Proceedings of the 2010 International Joint Conference on Neural Networks (IJCNN), Barcelona, Spain, 18-23 July 2010; pp. 1-8.

186. Mourad, M.; Bouzid, B.; Mohamed, B. A hybrid wavelet transform and ANFIS model for short term electric load prediction. In Proceedings of the 2012 2nd International Conference on Advances in Computational Tools for Engineering Applications (ACTEA), Beirut, Lebanon, 12-15 December 2012; pp. 292-295.

187. Sudheer, G.; Suseelatha, A. Pronóstico de carga a corto plazo usando la transformación wavelet combinada con Holt-Winters y modelos vecinos más próximos ponderados. Int. J. Electr. Power Energy Syst. 2015.

188. Guan, C.; Luh, P.B.; Michel, L.D.; Wang, Y.; Friedland, P.B. Very short-term load forecasting: Wavelet neural networks with data pre-filtering. IEEE Trans. Power Syst. 2012, 28, 30-41. [CrossRef]

189. Hochreiter, S.; Schmidhuber, J. Long short-term memory. Neural Comput. 1997, 9, 1735-1780. [CrossRef] [PubMed]

Publisher's Note: MDPI stays neutral with regard to jurisdictional claims in published maps and institutional affiliations. 